NBER WORKING PAPER SERIES

\title{
AGGREGATE IMPLICATIONS OF INDIVISIBLE LABOR
}

\author{
Casey B. Mulligan \\ Working Paper 8159 \\ http://www.nber.org/papers/w8159 \\ NATIONAL BUREAU OF ECONOMIC RESEARCH \\ 1050 Massachusetts Avenue \\ Cambridge, MA 02138 \\ March 2001
}

I gratefully acknowledge the comments of Robetr Barro, Hal Cole, Dan Hemermesh, Jim Heckman, Hendrik Houthakker, Bob Lucas, Andreu Mas-Colell, David Romer, Sherwin Rosen, Yona Rubenstein, Fernando Veloso, Yoram Weiss, Mike Woodford, anonymous referees and seminar participants at Harvard, the Richmond Fed and the Universities of Chicago and Virginia. Since this paper began as a bat with Pat Kehoe (I lost), I am obligated to thank Pat for research assistance. Silve Parviainen and Jose Maria Liberti also provided able research assistance. The views expressed herein are those of the author and not necessarily those of the National Bureau of Economic Research.

(C) 2001 by Casey B. Mulligan. All rights reserved. Short sections of text, not to exceed two paragraphs, may be quoted without explicit permission provided that full credit, including $\mathbb{C}$ notice, is given to the source. 
Aggregate Implications of Indivisible Labor

Casey B. Mulligan

NBER Working Paper No. 8159

March 2001

JEL No. J22, D1 1

\section{ABSTRACT}

I suggest that the aggregate implications of indivisible labor are few, and subtle. First, I model behavior in an "indivisible labor" environment like those of Diamond and Mirrlees (1978, 1986), Hansen (1985), Rogerson (1988), Christiano and Eichenbaum (1992) and show that aggregate behavior in such an economy is indistinguishable from aggregates generated by the divisible labor model of Lucas and Rapping (1969); any data on aggregate hours and earnings generated by the divisible (indivisible) model can be generated by a similar parameterization of the indivisible (divisible) model. Second, I generalize the aforementioned models of indivisible labor to allow for labor supply on the "intensive" margin, and to allow for nonlinear taxes. The aggregate implications of doing the former are quite subtle, but doing the latter suggests that the indivisibility of labor may have implications for public finance. My results also imply that backward bending aggregate labor supply, and any nonnegative degree of aggregate intertemporal substitution, are consistent with standard economic theory even when all labor is supplied on the so-called "extensive" margin. Finally, my results suggest that the classic aggregate studies of labor supply by Mincer, Bowen and Finegan, and others have a simple microeconomic interpretation.

Casey B. Mulligan

Department of Economics

University of Chicago

1126 East $59^{\text {th }}$ Street

Chicago, IL 60637

and NBER

c-mulligan@uchicago.edu 


\section{Table of Contents}

I. Introduction $\ldots \ldots \ldots \ldots \ldots \ldots \ldots \ldots \ldots \ldots \ldots \ldots \ldots \ldots \ldots \ldots$

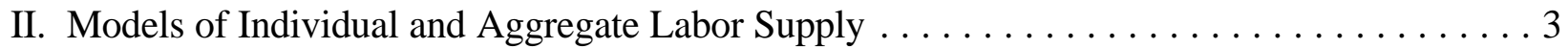

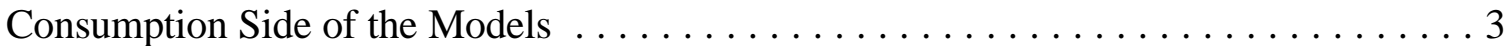

Lucas and Rapping's Divisible Representative Agent Model . . . . . . . . . . . . . . . 3

Micro-level Indivisible Labor, Employment Lotteries $\ldots \ldots \ldots \ldots \ldots \ldots \ldots$

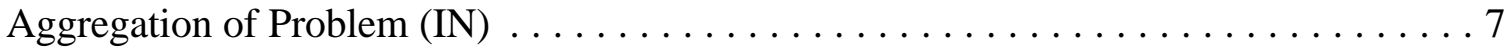

Divisible and Indivisible Models Generate the Same Macro Data . . . . . . . . . . . . 10

Divisible and Indivisible Models Have the Same Welfare Implications $\ldots . . \ldots \ldots 12$

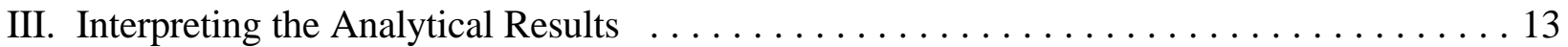

Just a Bit of Aggregation Renders Indivisibility Invisible . . . . . . . . . . . 13

Lotteries and Contingent Claims - Realistic or Analytically Convenient? . . . . . . 16

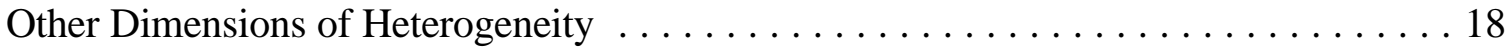

Aggregate Studies of Employment have a Simple Microeconomic Interpretation . . . 20

The Logical Possibility of Backward-Bending Aggregate Labor Supply . . . . . . . . 23

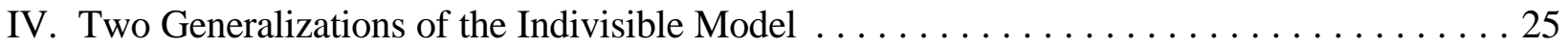

"Intensive" and "Extensive" Margins in Divisible and Indivisible Economies . . . . . . . . 26

Time-Aggregated Nonlinear Tax Rules . . . . . . . . . . . . . . . . . . . . 29

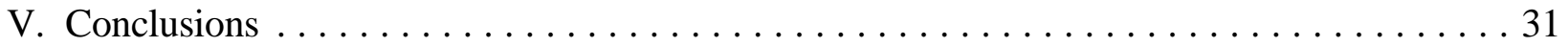

VI. Appendix I: Individual and Aggregate Labor Supply with Consumption-Leisure Nonseparabilities

VII. Appendix II: The Distribution of Reservation Wages without Transfers . . . . . . . . . 37

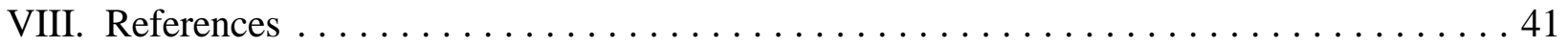


"A small fall in the price of hats or watches will not affect the action of everyone; but it will induce a few persons, who were in doubt whether or not to get a new hat or a new watch, to decide in favor of doing so. ...But the economist has little concern with particular incidents in the lives of individuals ...the variety and fickleness of individual action are merged in the comparatively regular aggregate of the action of many." Alfred Marshall, Principles of Economics, III.iii.5.

\section{Introduction}

Employment is an important “margin” of labor supply (Coleman 1984, Heckman 1993) and many have emphasized the micro-econometric implications of discrete choice in the labor market. But what are the implications of "indivisible labor" for aggregate data - measures of economic activity that are aggregated over time and across people? Some such as Hansen (1985), Hansen and Sargent (1988), Rogerson (1988), Plosser (1989), Greenwood and Hercowitz (1991), Kydland and Prescott (1991), Christiano and Eichenbaum (1992), and Cho and Cooley (1994) have argued that the indivisibility of labor means that there is a lot - even infinite - substitution of work over time. Others (e.g., Ashenfelter 1980, p. 547) suggest that the importance of the employment margin relative to the "hours" margin reflects labor market inflexibilities permitting little substitution of work over time. Others (e.g., Ben Porath 1973, Heckman 1978) do not take a stand on this issue, emphasizing instead that aggregate labor supply is necessarily a complicated function of individual behavior and heterogeneity, although Ben Porath agrees that the substitution effect of a wage change on aggregate employment must in theory exceed its wealth effect.

The purpose of this paper is to analytically characterize, for an indivisible economy which has some of the above models as special cases, the relationship between individual heterogeneity and aggregate "labor supply." This analytical characterization, when compared with that of a "divisible" labor model, shows how (a) micro-level indivisibility of labor per se need not have implications for aggregate data and (b) the classic aggregate studies of labor supply by Bowen and Finegan (1969), Lucas and Rapping (1969), Mincer (1962), and others are consistent with the apparent importance

of the "employment margin" and have a simple microeconomic interpretation. In a sense, my proofs are labor supply cousins of proofs in the production literature (e.g., Houthakker 1955) showing how aggregate production functions can be simple, smooth, and regular even when firm-level production possibilities are not smooth. 
One definition of "indivisibility" is common in the labor and macroeconomics literatures (e.g., Diamond and Mirrlees (1978, 1986), Hansen (1985), Rogerson (1988), Hamilton (1988), Christiano and Eichenbaum (1992)): work during some time interval must occur for exactly $\bar{n}$ units of time or there be no work at all. For example, the time interval might be a week with a person working exactly forty hours during a week or not working at all. This indivisible environment can be contrasted with the "divisible" labor environment described by Lucas and Rapping (1969, hereafter LR) where workers may choose to work any fraction of any time interval. I show how any aggregate data generated by the divisible labor economy can be generated by a similar parameterization of the indivisible economy. Conversely, any aggregate data generated by the indivisible labor economy can be generated by a similar parameterization of the divisible economy. Hence, the micro-level indivisibility of labor does not by itself justify the constant marginal disutility of work assumed by Hansen (1985), Hansen and Sargent (1988), Rogerson (1988), Plosser (1989), Greenwood and Hercowitz (1991), Kydland and Prescott (1991), Christiano and Eichenbaum (1992), Cho and Cooley (1994), Crucini and Kahn (1996), Wu and Zhang (2000), and others in the literature. Moreover, my result is stronger than Marshall's claim that micro-indivisibility is "regularly merged" in the aggregate: the equivalent pair of divisible and indivisible economies can be so similar in other micro-dimensions that the continuous and regular aggregate labor supply function generated by the economy with micro-level indivisibilities has a very simple microeconomic interpretation. This means, for example, that the substitution effect of a wage change on aggregate employment may in theory be less than its wealth effect. Such "backward-bending" aggregate labor supply can occur even when all labor is supplied on the extensive margin, as long as some wage income is pooled over time or across persons, because the extra wage income enjoyed in some working periods (or by some working people) is used to finance nonwork in some other working period (or by some other workers).

My basic results leave open the possibility that generalizations of the indivisible model might have aggregate implications. I explore two such generalizations. The first shows how a model of time aggregation and indivisible labor, while consistent with any nonnegative aggregate wage elasticity of labor supply, might imply restrictions on the aggregate relation between employment rates and hours - namely that hours per employee be less wage sensitive than employment rates at low employment rates and more wage sensitive at high employment rates. Nonlinear and timeaggregated tax rules are the second and more interesting generalization, suggesting that divisible and 
indivisible models may be different in terms of their predictions for responses to distortionary taxes. This is not a point made by Hansen (1985) and those in the literature who have followed, but the interactions between indivisibility and government policy may imply that labor supply is relatively unresponsive to marginal tax rates.

\section{Models of Individual and Aggregate Labor Supply}

\section{II.A. Consumption Side of the Models}

Individuals in the models care about their lifetime consumption and its allocation over time. However, the intertemporal consumption allocation is not of particular interest here, so my analysis uses a "consumption value function" $U(c)$ to summarize this part of a consumer's decision problem:

$$
U(c) \equiv \max _{\substack{\left\{c_{t}\right\}_{t=1}^{T} \\ \text { s.t. }}} u\left(c_{1}, c_{2}, \ldots, c_{T}\right) \quad \text { s.t. } \sum_{t=1}^{T} e^{-\rho(t-1)} Q_{t} c_{t} \leq c
$$

where $T \geq 1$ and $e^{-\rho(t-1)} Q_{t}$ is the period $t$ interest rate factor. The function $U(c)$ depends on the rate of time preference $\rho$ and sequence of interest rate factors $\left\{Q_{t}\right\}$, but its dependence is not relevant for the results to be proved and is therefore suppressed by my notation. $c$ may be interpreted as the lifetime present value of consumption.

Implicit in my use of a consumption value function in the analysis of labor supply is the assumption that consumption and leisure are separable: a different rate of growth of consumption (leisure) does not mean a different intertemporal marginal rate of substitution of leisure (consumption). My Appendix I extends the analysis to utility functions that are not separable in consumption and leisure; consumption-leisure separability is featured in the main text in order to derive more transparent results and to facilitate comparisons with previous studies of indivisible labor which typically have assumed separability.

\section{II.B. Lucas and Rapping's Divisible Representative Agent Model}

As a contrast to the indivisible labor model, it is useful to begin by introducing a divisible labor environment. During a time interval - whose length I normalize to one - the representative individual 
may work from anywhere from 0 to $n_{\max }$ units of time. Time interval $t$ work is paid at wage rate $w_{t}$. The present value of lifetime consumption $C$ is financed out of the present value of lifetime earnings and an initial asset stock $a$.

The problem (LR) describes the representative agent's labor supply decisions when labor is perfectly divisible. I denote the choice variables with capital letters $C, N_{1}, N_{2}$, etc to emphasize that the LR model is a model of aggregates.

\section{(LR) Optimal Divisible Labor in Discrete Time}

$$
\begin{gathered}
\max _{C,\left\{N_{t}\right\}_{t=1}^{T}} U(C)-\sum_{t=1}^{T} e^{-\rho(t-1)} g_{t} v\left(N_{t}\right) \\
\text { s.t. } N_{t} \in\left[0, n_{\max }\right] \quad, \quad C=a+\sum_{t=1}^{T} e^{-\rho(t-1)} Q_{t} w_{t} N_{t}
\end{gathered}
$$

where $N_{t}$ is aggregate time worked during time period $t, \rho$ is the rate of time preference, $g_{t}$ is an aggregate preference parameter, $a$ is the consumer's initial asset holdings, $w_{t}$ is the period $t$ wage rate, and $Q_{t}$ is the period $t$ interest rate factor (defined net of the rate of time preference).

Because of the assumed separability over time and the assumed separability of consumption and leisure, (LR) is a special case of the LR (1969) model. ${ }^{1}$ Like LR's (1969) model, any amount of time worked in the interval $\left[0, n_{\max }\right]$ is feasible in each time interval for a (LR) consumer.

For simplicity, I assume that the function $v(N)$ does not vary over time although the marginal disutility of work schedule varies over time to the extent that the parameter $g_{t}$ varies. I make two assumptions (A1)-(A2) and one normalization (A3) about the disutility of work $v(N)$ defined on $\left[0, n_{\max }\right]:^{2}$

$$
\text { (A1) } \quad v^{\prime}(N)>0
$$

${ }^{1}$ LR's empirical specifications implicitly assume something like separability within and across periods.

${ }^{2}$ (A3) is a normalization because, if $\ln v^{\prime}(N)$ integrated to some number $\varepsilon \neq 0$, then same marginal disutility of work could be represented by redefining the parameter $g$ as $g \mathrm{e}^{\varepsilon}$ and redefining $v(N)$ as $g \mathrm{e}^{-\varepsilon} v(N)$. 
(A2) $\quad v^{\prime \prime}(N)>0$

$$
n_{\max }
$$$$
\int_{0} \ln v^{\prime}(N) d N=0
$$

(A4) $\quad U^{\prime}(C)>0, U^{\prime \prime}(C) \leq 0$

(A4) are the usual assumptions about the marginal utility of wealth.

It will be useful to define a "parameterization" of (LR) to be $\left(a, \rho, n_{\max },\left\{w_{p} g_{t}, Q_{t}\right\}\right) \in \mathbb{R}^{2} \times \mathbb{R}_{+}^{3 T+1}$. Wages and interest rates may be determined as part of a general equilibrium (as they are in Hansen (1985) and Rogerson (1988)), but they are parameters from the point of view of a consumer's decision problem.

The first order conditions for the problem (LR) equate the marginal disutility of work to the marginal utility of wealth times the discounted wage:

$$
g_{t} v^{\prime}\left(N_{t}\right)=U^{\prime}(C) Q_{t} w_{t} \quad t=1, \ldots, T
$$

Together with the intertemporal budget constraint, the first order conditions (1) determine the optimal lifetime sequence of labor supply.

According to equation (1), the date $t$ Frisch labor supply curve (namely, the graph of $N_{t}$ vs. $\ln w_{t}$ holding the marginal utility of wealth $U^{\prime}(C)$ constant) is just the inverse of the log of the marginal disutility of work schedule (i.e., the inverse of $\left.\ln v^{\prime}(\cdot)\right)$. The Frisch labor supply curve is worth noting because, as I show below, an analysis of it permits some mathematically simple comparisons of divisible and indivisible economies.

\section{II.C. Micro-level Indivisible Labor, Employment Lotteries}

In the indivisible model, an individual must either work 0 or $\bar{n}$ hours during a time interval. 
Any amount of work between 0 and $\bar{n}$ is not feasible for an individual. ${ }^{3}$ Time interval $t$ work is productive at rate $w_{t}$, so an individual's labor product during time interval $t$ can be either 0 or $w_{t} \bar{n}$.

Of course, the average time worked for a group of people during a time interval can be between 0 and $\bar{n}$, and average labor product between 0 and $w_{t} \bar{n}$.

In order to model an individual labor's supply in an indivisible environment, one might write down an individual-level replicate of the (LR) model, and add the restriction that work in each time interval be chosen from the set $\{0, \bar{n}\}$. Aggregates could then be modeled by integrating individual choices across individuals. However, this approach is analytically inconvenient because the individual choice problem is nonconvex. An alternative approach for modeling individual behavior in such an environment is to allow for trade in lotteries.

Consider consumers who choose a sequence of lotteries $\left\{L_{t}\right\}$ offered by employers. The date $t$ lottery is: (1) an allowance $\omega_{t}$ and (2) a probability of working $\pi_{t}$ Consumers receive their allowance at the beginning of the period regardless of the outcome of the lottery. The firm has property rights over the labor output $w_{t} \bar{n}$ produced by each consumer chosen by the lottery to work. The market for lotteries is competitive, so the only lotteries that will be traded are the actuarially fair ones, which must satisfy $\omega_{t}=\pi_{t} w_{t} \bar{n}$. In words, the allowance equals the expected labor product.

As a result of separable utility and trade in these lotteries, an individual's labor supply is stochastic, but his consumption is deterministic. Given a sequence of lotteries and a lifetime preference profile, an individual's expected lifetime utility is calculated as:

$$
E\left[U(c)-\sum_{t=1}^{T} e^{-\rho(t-1)} \gamma_{t} n_{t} \mid\left\{\pi_{t}, \gamma_{t}\right\}_{t=1}^{T}\right]=U(c)-\sum_{t=1}^{T} e^{-\rho(t-1)} \gamma_{t} \pi_{t} \bar{n}
$$

where $n_{t}$ is period $t$ time worked and $\gamma_{t}$ is a preference parameter. Here I am building a model of individual labor supply, so my notation distinguishes $n_{t}, \gamma_{t}$ and $c$ from the aggregates $N_{t}, g_{t}$, and $C$ in

${ }^{3}$ Hansen (1985, p. 312) and others suggest that this indivisibility derives from fixed costs of traveling to work, setting up the work day, or obtaining a job. Based on the suggestions of Chapman (1909), Mulligan (1999) builds an explicit continuous time mathematical model of fixed costs and the optimal bunching of work in time, and shows how aggregates (over time and across persons) of such a model are indistinguishable from the (IN) and (LR) models. He notes one exception, which I note in Section IV.A below. 
problem (LR).

Notice that I have used an individual utility function that has linear disutility of work $\gamma_{t} n$. But also notice that this linearity is of no consequence in an indivisible environment: we could start with any nonlinear disutility of work function $v_{t}\left(n_{t}\right)$, normalize $v_{t}(0)=0$, define $v_{t}(\bar{n})=\gamma_{t} \bar{n}$, and have exactly the utility function above.

With this notation, it is straightforward to mathematically model an individual's behavior in an indivisible environment where there is trade in such lotteries. The problem (IN) is such a model:

\section{(IN) Indivisible Labor in Discrete Time}

$$
\begin{gathered}
\max _{C,\left\{\pi_{t}\right\}_{t=1}^{T}} U(c)-\sum_{t=1}^{T} e^{-\rho(t-1)} \gamma_{t} \pi_{t} \bar{n} \\
\text { s.t. } \pi_{t} \in[0,1] \quad, \quad c=a+P(\Gamma)+\sum_{t=1}^{T} e^{-\rho(t-1)} Q_{t} w_{t} \pi_{t} \bar{n}
\end{gathered}
$$

where $a+P(\Gamma)$ is the consumer's initial wealth (more on $P(\Gamma)$ below). As in (LR), $w_{t}$ is the period $t$ wage rate and $e^{-\rho(t-1)} Q_{t}$ is the period $t$ interest rate factor. Notice that the marginal disutility of work during time interval $t e^{-\rho(t-1)} \gamma_{t}$ can, in addition to a constant rate of discount, vary over time.

\section{II.D. Aggregation of Problem (IN)}

In order to model aggregate labor supply in the indivisible environment, I aggregate the behavior of heterogeneous individuals solving problem (IN). Two assumptions are used in the aggregation, the first of which is (A5):

(A5) There are a continuum of individuals solving the problem (IN) who differ only according to their life cycle disutility of work profile $\Gamma=\left\{\gamma_{1}, \gamma_{2}, \ldots, \gamma_{\mathrm{T}}\right\} \in \mathbb{R}_{+}^{\mathrm{T}}$. The geometric mean preference parameter in period $t, g_{t}$, varies over time but the distribution $\mathrm{F}$ of preferences around that mean is the same every period: 


$$
\begin{gathered}
\ln \gamma_{t}-\ln g_{t} \sim F \quad \text { all } t \\
\int x d F(x)=0
\end{gathered}
$$

$\mathrm{F}$ is assumed to be once differentiable and strictly increasing on its support $\left[x_{1}, x_{2}\right]$, and known to all agents.

Notice that (A5) requires consumers to have the same market value of time $w_{t}$ and same interest rate factor $Q_{t}$ at each date as well as the same rate of time preference $\rho$. These might be sources of heterogeneity that are potentially interesting for macroeconomics, but Section III.C shows that this heterogeneity is not particularly related to the indivisibility of labor. Also notice that (A5) makes no restrictions on the lifetime serial correlation of an individual's marginal disutility of work.

Consumers also have one component of their wealth, $a$, the same. Assumption (A6) describes the heterogeneity of the other component, $P(\Gamma)$.

(A6) Before their lifetime preference profiles $\Gamma=\left\{\gamma_{1}, \gamma_{2}, \ldots, \gamma_{\mathrm{T}}\right\}$ are revealed at date 0 , (IN) consumers choose an insurance contract $P(\Gamma)$ that has expected value zero and maximizes the expected value of the problem (IN), where expectations are with respect to $\Gamma$. Ex ante, each consumer has the same probability of drawing any particular preference profile.

There will be heterogeneity of tastes in an economy generated by aggregating (IN) according to (A5). Some consumers are "unlucky" enough to hate work in those periods when it is most profitable, luck which affects the marginal utility of wealth $U(c)$ in the problem (IN). The insurance contracts specified by (A6) compensate unlucky consumers (and penalize lucky consumers) in just the right amounts to guarantee the solutions to (IN) have the same marginal utility of wealth regardless of $\Gamma$.

In this model, consumer $i$ 's date $t$ choice of employment lottery is determined according to: 


$$
\pi_{t}^{i}\left\{\begin{array}{rlr}
=0 & \text { if } & \gamma_{t}^{i}>Q_{t} w_{t} U^{\prime}(c) \\
\in(0,1) & \text { if } & \gamma_{t}^{i}=Q_{t} w_{t} U^{\prime}(c) \\
=1 & \text { if } & \gamma_{t}^{i}<Q_{t} w_{t} U^{\prime}(c)
\end{array}\right.
$$

Because of the date zero trade in insurance contracts, consumption $c$ and the marginal utility of wealth $U^{\prime}(c)$ does not vary across consumers and is therefore not indexed by $i$. In the three cases listed above, two of them are the "trivial" lotteries $\pi=0$ and $\pi=1$. Nontrivial lotteries occur only when $\gamma_{t}=Q_{t} w_{t} U^{\prime}(c)$ which - given the continuity of $F$ and the equality of $Q_{t} w_{t} U^{\prime}(c)$ across consumers - is a measure zero event.

It is convenient to define the date $t$ "reservation wage" person $i$ to be the marginal adjusted present value $e^{4}$ of nonwork time for the consumer, or $\hat{w}_{t}^{i} \equiv \gamma_{t}^{i} / U^{\prime}(c) .^{5}$ Work occurs with positive probability at date $t$ whenever $Q_{t} w_{t}$ (namely, the adjusted present value of the market wage) equals or exceeds $\hat{w}_{t}^{i}$.

The fraction $\Pi_{t}$ of consumers working at date $t$ is $\mathrm{F}\left(\ln \left(Q_{t} w_{t} U^{\prime}(c) / g_{t}\right)\right)$. Define $N_{t}$ to be the date $t$ average labor supply. $N_{t}$ is computed according to:

$$
N_{t}=\Pi_{t} \cdot \bar{n}+\left(1-\Pi_{t}\right) \cdot 0=F\left(\ln \frac{Q_{t} w_{t} U^{\prime}(c)}{g_{t}}\right) \bar{n}
$$

Since the average insurance premium or award paid at date zero must be zero, an average

${ }^{4}$ As in most life cycle models, "adjusted present value" reflects discounting at the interest rate net of the rate of time preference. Recall that the interest rate factor making this adjustment is denoted $Q_{t}$ in my model.

${ }^{5}$ There are a variety of reasonable definitions of "reservation wage," but $\hat{w}_{t}^{i}$ is most convenient for my purposes. Also notice that $\hat{w}_{t}{ }^{i}$ is, holding constant the wages for all other persons in the economy, the highest wage for person $i$ for which a utilitarian planner would assign work to person $i$ with probability zero. 
budget constraint can easily be computed by averaging the (IN) budget constraint across consumers:

$$
C=a+\sum_{t=1}^{T} e^{-\rho(t-1)} Q_{t} w_{t} N_{t}
$$

Notice the similarity of this average budget constraint with the budget constraint for the divisible problem (LR). The average budget constraint (3), the equations (2), and the equation $c=C$ determine average labor supply at each date.

\section{II.E. Divisible and Indivisible Models Generate the Same Macro Data}

According to equation (2), the date $t$ aggregate Frisch labor supply curve (namely, the graph of $N_{t}$ vs. $\ln w_{t}$ holding the marginal utility of wealth $U^{\prime}(c)$ constant) is just the CDF for the taste parameter $\ln \gamma$. As discussed above, the (LR) model's Frisch labor supply curve is just the inverse of the log of the marginal disutility of work schedule. Hence, a comparison of the Frisch labor supply curves for the two economies suggests that the aggregate "disutility of work" is isomorphic with the cross-sectional distribution of tastes.

In order to prove this more rigorously, it is useful to define an aggregate "parameterization" of (IN) to be $\left(a, \rho, \bar{n},\left\{w_{p} g_{v}, Q_{t}\right\}\right) \in \mathbb{R}^{2} \times \mathbb{R}_{+}{ }^{3 T+1}$. Notice that, like the aggregate problem (LR), the aggregation of the problem (IN) has exactly $3 T+3$ parameters. Propositions 1 and 2 below show how, when (LR) and (IN) are parameterized in the same way, they generate the same aggregate data.

Proposition 1 When aggregated across individuals according to (A5) and (A6), aggregate data on earnings and hours $\left\{N_{t} w_{t} N_{t}\right\}$ for any parameterization of the problem (IN) are identical to the aggregate data $\left\{N_{t} w_{t} N_{t}\right\}$ generated by some parameterization of the problem (LR).

Proof (i) Choose any set of parameters $\left(a, \rho, \bar{n},\left\{w_{p} g_{t}, Q_{t}\right\}\right) \in \mathbb{R}^{2} \times \mathbb{R}_{+}^{3 T+1}$ for the problem (IN).

(ii) When aggregated according to (A5) and (A6), average hours $\left\{\mathrm{N}_{t}\right\}$ satisfy (2) and (3), and $c=$ $C$.

(iii) Choose the same parameters $\left(a, \rho, n_{\max }\left\{w_{p} g_{p} Q_{t}\right\}\right)$ for the problem (LR) and choose any disutility 
of wealth function $v(N)$ that satisfies:

$$
v^{\prime}(N) \equiv e^{F^{-1}(N / \bar{n})}
$$

with $F^{-1}$ defined at the end points according to $F^{-1}(0)=x_{1}$ and $F^{-1}(1)=x_{2}$. Notice that any such $v(N)$ is continuous and satisfies $v^{\prime}(N)>0, v^{\prime \prime}(N)>0$, and the normalization (A3).

(iv) According to the first order conditions of the problem (LR), average hours $\left\{N_{t}\right\}$ must satisfy equation (1).

(v) By definition of the problem (LR), average hours $\left\{N_{t}\right\}$ satisfy equation (3).

Proposition 2 The aggregate data $\left\{N_{t} w_{p} N_{t}\right\}$ generated by any parameterization of the problem (LR) are identical to the aggregate data $\left\{N_{t} w_{t}, N_{t}\right\}$ obtained by aggregating some parameterization of the problem (IN) across individuals according to (A5) and (A6).

Proof (i) Choose any set of parameters $\left(a, \rho, n_{\max },\left\{w_{p} g_{v}, Q_{t}\right\}\right) \in \mathbb{R}^{2} \times \mathbb{R}_{+}^{3 T+1}$ for the problem (LR) (ii) According to the first order conditions of the problem (LR), average hours $\left\{N_{t}\right\}$ must satisfy equation (1).

(iii) By definition of the problem (LR), average hours $\left\{N_{t}\right\}$ satisfy equation (3).

(iv) Choose the same parameters $\left(a, \rho, \bar{n},\left\{w_{p} g_{t}, Q_{t}\right\}\right)$ for the problem (IN) and choose the distribution function $F$ according to:

$$
F(x) \equiv\left\{\begin{aligned}
0 & \text { if } \quad x<\ln v^{\prime}(0) \\
\frac{\phi\left(e^{x}\right)}{n_{\max }} & \text { if } \quad x \in\left[\ln v^{\prime}(0), \ln v^{\prime}\left(n_{\max }\right)\right] \\
1 & \text { if } \quad x>\ln v^{\prime}\left(n_{\max }\right)
\end{aligned}\right.
$$

where $\phi$ is the inverse of $v^{\prime}(N)$, the marginal disutility of work. Notice that any such $F(x)$ satisfies $F \in[0,1], F^{\prime}(x)>0$, and the normalization for $F$ displayed in (A5).

(v) When aggregated according to (A5) and (A6), average hours $\left\{N_{t}\right\}$ from (IN) satisfy equations 
(2), (3), and $c=C$.

\section{II.F. Divisible and Indivisible Models Have the Same Welfare Implications}

Because there is some heterogeneity in the indivisible model but not in the divisible model, it is only meaningful to compare aggregate welfare calculations for the two models. Propositions 3 and 4 show there are at least two sensible ways of aggregating welfare in the indivisible model to produce calculations identical to their divisible counterparts:

Proposition 3 When the problem (IN) with rate of time preference $\rho$, maximum hours $\bar{n}$, interest rate factors $\left\{Q_{t}\right\}$, and average preference profile $\left\{g_{t}\right\}$ is aggregated across individuals according to (A5) and (A6), the average willingness to pay for wage increase at any date $t$ is the same as the willingness to pay in problem (LR) with rate of time preference $\rho$, maximum hours $\bar{n}$, interest rate factors $\left\{Q_{t}\right\}$, and preference profile $\left\{g_{t}\right\}$.

Proof (i) In current value terms, the willingness to pay for a marginal increase in $w_{t}$ is $N_{t}$ in the divisible model. This follows from Roy's Identity.

(ii) In current value terms, the willingness to pay for a marginal increase in $w_{t}$ (taking his insurance premium $\mathrm{P}(\Gamma)$ as given) is $\pi_{t} \bar{n}$ for an individual in the indivisible model who purchases a date $t$ employment lottery offering probability $\pi_{t}$. This follows from Roy's Identity.

(iii) The average willingness to pay in the indivisible model is the average of $\pi_{t} \bar{n}$, which is $N_{t}$.

(iv) Propositions 1 and 2 show that both models generate the same average labor supply $N_{t}$, so the average willingness to pay is the same.

Notice that the wage change hypothesized by Proposition 3 is not insured and the willingness to pay varies across individuals in the indivisible model. Proposition 4 considers the willingness to pay for insurable wage changes before each individual's preferences are revealed, defining "indirect utility functions" for each model. $V\left(a,\left\{w_{t}\right\}\right)$ denotes the maximized value of the representative agent's problem (LR) and $\tilde{V}\left(a,\left\{w_{t}\right\}\right)$ the maximized value of (IN) averaged across individuals.

Proposition 4 When the problem (IN) with rate of time preference $\rho$, maximum hours $\bar{n}$, interest rate 
factors $\left\{Q_{t}\right\}$, and average preference profile $\left\{g_{t}\right\}$ is aggregated across individuals according to (A5) and (A6), each individual's ex ante expected indirect utility $\tilde{V}\left(a,\left\{w_{t}\right\}\right)$ has the same derivatives as the indirect utility $V\left(a,\left\{w_{t}\right\}\right)$ for problem (LR) with rate of time preference $\rho$, maximum hours $\bar{n}$, interest rate factors $\left\{Q_{t}\right\}$, and preference profile $\left\{g_{t}\right\}$.

Proof (i) Note that, for the problem (LR), $\partial V / \partial a=U^{\prime}(C)$ and $\partial V / \partial w_{t}=U^{\prime}(C) e^{-\rho(t-1)} Q_{t} N_{t}$.

(ii) The expected indirect utility for the problem (IN) is:

$$
\begin{gathered}
\tilde{V}\left(a,\left\{w_{t}\right\}_{t=1}^{T}\right)=U\left(a+\sum_{t=1}^{T} e^{-\rho(t-1)} Q_{t} w_{t} N_{t}\right)-\sum_{t=1}^{T} e^{-\rho(t-1)} \bar{n} \int_{-\infty}^{\ln \lambda Q_{t} w_{t}} e^{x} d F(x) \\
\lambda \equiv U^{\prime}\left(a+\sum_{t=1}^{T} e^{-\rho(t-1)} Q_{t} w_{t} N_{t}\right)
\end{gathered}
$$

(iii) Using the expression above and the definition of $N_{t}$ for the problem (IN), it is straight-forward to show $\partial \tilde{V} / \partial a=U^{\prime}(C)$ and $\partial \tilde{V} / \partial w_{t}=U^{\prime}(C) e^{-\rho(t-1)} Q_{t} N_{t}$.

(iv) Since $N_{t}$ is the same function of $\left(a,\left\{w_{t}\right\}\right)$ for the two models, higher order derivatives are the same for $V$ and $\tilde{V}$.

Proposition 4 derives an equivalence between the indirect utility function for (LR) and an aggregate indirect utility function defined for (IN). Thus Proposition 4 displays another sense in which the aggregate willingness to pay for an aggregate wage change is the same in the two models.

\section{Interpreting the Analytical Results}

\section{III.A. Just a Bit of Aggregation Renders Indivisibility Invisible}

When aggregated across individuals, the indivisible models of Diamond and Mirrlees (1978, 1986), Hansen (1985), Hamilton (1988), Rogerson (1988), Christiano and Eichenbaum (1992) and many others are equivalent to the divisible model of Lucas and Rapping (1969) defined over aggregated measures. Thus, I argue that labor indivisibility (as modeled by these authors) per se has no implications for aggregate labor market data. Although such an aggregation result may not be particularly surprising - for example, Marshall suggests this in his Principles of Economics 
(1920/1990), Hamermesh (1990) derives a smooth labor demand function in a micro model of lumpy adjustment costs, and Hildenbrand (1974) demonstrates the smoothness of aggregate behavior in economies with a continuum of agents - I am able to be precise about the mapping between the heterogeneity and the smoothness of well known models of aggregate behavior. Indeed, the marginal disutility of work schedule from the divisible model is nothing more than the inverse CDF from the indivisible model, and vice versa. Houthakker's (1955) proof - that the input demands of heterogeneous Leontief firms can aggregate to a smooth industry demand - is in this regard a closer and more well-known analytical cousin to my result. Houthakker's "fixed proportion" is analogous to my labor indivisibility $\bar{n}$ while each of his firm's profit is analogous to my reservation wage. Houthakker generates Cobb-Douglas input demand by aggregating across firms with identical profits (namely zero) and fixed proportions distributed Pareto. My Proposition 1 generates (in a special case) Cobb-Douglas labor supply by aggregating across consumers with identical "fixed proportions" $(\bar{n})$ and reservation wages distributed exponential. My proof requires trade in contingent claims, and Houthakker's does not, because we suppose that consumers maximize a nonlinear objective (utility) while firms maximize a linear one (profits). Both models place upper limits on the amount supplied by a particular agent (workers in mine, producers in his), limits which may be more realistic in my application than in his.

If we construct an economy of individuals solving the problem (IN) with preferences constant over time and across persons, and with production depending on aggregate labor input, we have the deterministic version of Hansen's (1985) model. To see this, notice that a nontrivial measure of agents may demand nontrivial employment lotteries. Furthermore, because each agent has the same ex post preference profile $\Gamma$, the only equilibrium date zero insurance contract is $P(\Gamma)=0$. In this homogeneous special case, there exists a sequence of wages and interest rates $\left\{w_{p} Q_{t}\right\}$ so that, in Hansen's (1985, p. 318) words, "the elasticity of substitution between leisure in different periods for the 'representative agent' is infinite." Hansen also shows that indivisibility is not necessary to deliver this result - a quasilinear version of LR's divisible model (i.e., $v(N)$ linear in $N$ ) also implies infinite substitutability over time (see also my Proposition 1). However, my Proposition 2 shows that indivisible labor is not sufficient to deliver infinite or even substantial substitution over time, or to deliver the aggregate wealth effects that are to be expected when agents have quasilinear utility (i.e., no pure wealth effect on consumption). This point is important and quite contrary to the spirit of 
Hansen's and Rogerson's papers (as well as later papers by Cho, Cooley, Kydland, and Prescott), so I demonstrate it in an example.

Choose any set of parameters $\left(a, \rho, \bar{n},\left\{w_{t} g_{t} Q_{t}\right\}\right) \in \mathbb{R}^{2} \times \mathbb{R}_{+}{ }^{3 \mathrm{~T}+1}$ for the problem (IN) and aggregate solutions across individuals according to (A5) and (A6), taking the distribution function $F(x)=e^{x / 100} / \bar{n}$ with support $[-\infty, 100 \ln \bar{n}]$. Proposition 1 shows that the same aggregate data can be generated by the LR model with $v^{\prime}(N) \equiv N^{100}$. This model has practically no scope for substitution over time: the intertemporal elasticity of substitution is $1 / 100$. Furthermore, wealth effects in this model are very different than they are in Hansen-Rogerson quasilinear special cases of the LR model.

My proofs therefore show how Hansen's (1985) and Rogerson's (1988) findings of an infinite equilibrium aggregate labor supply elasticity are not a consequence of indivisibility, but of (a) the homogeneity of micro-level decisions, and (b) their definition of equilibrium. My Propositions contradict Rogerson's (1988, pp. 3, 14) claims that indivisibility implies large aggregate labor supply elasticities even when agents are heterogeneous in terms of their reservation wages. Nor is it true that substitution along the "extensive" margin must be greater than substitution along the "intensive" margin. Rogerson (1988, p. 14) defends his claims with a parametric example, but a comparison that example with my Proposition 2 shows how Rogerson's example still has a degenerate distribution of reservation wages $^{6}$ despite the existence of some heterogeneity of tastes. Indeed, any nonnegative aggregate labor supply elasticity can be generated by either a divisible or an indivisible model.

In a sense, Hansen's and Rogerson's lotteries are a source of preference heterogeneity because they divide the population into two groups - those who work and those who do not. But the "heterogeneity" is not revealed until after agents have made their decisions for the period. ${ }^{7}$ Hence Hansen-Rogerson agents must all make the same decisions and, when those decisions are discrete, aggregate behavior must be discrete. Under this interpretation, my departure from Hansen and Rogerson is that heterogeneity is revealed before decisions are made and, as a result, agents make different decisions which are continuous in the aggregate even when discrete at the micro level.

${ }^{6}$ Recall that, in the context of a model with employment lotteries, I define a person's "reservation wage" to be his utility cost of a marginal increase in the probability of employment.

${ }^{7}$ I owe this point to Robert Lucas, Jr. 


\section{III.B. Lotteries and Contingent Claims - Realistic or Analytically Convenient?}

The (IN) model is a simple and analytically convenient way to think about aggregate labor supply in economies with indivisibilities and utility maximization because the aggregate labor supply is the same as an otherwise equivalent (LR) economy, and the aggregate labor supply curve is nothing more than a cumulative distribution function. Including employment lotteries in the model also facilitates comparisons with Hansen's and Rogerson's models in which workers also trade employment lotteries. But can the (IN) model, with its employment lotteries and "tastes insurance," be empirically relevant? After all, many sources of labor market data (e.g., the CPS), do not appear to say much about employment lotteries or tastes insurance. Regarding the employment lotteries, it is worth noting that, according to the (IN) model, only the trivial lotteries $\pi=0$ and $\pi=1$ are demanded in the competitive equilibrium. This happens in the model because heterogeneity of consumer tastes and date zero trade in consumption insurance ${ }^{8}$ result in a continuous distribution of gaps between market and reservation wages, and nontrivial lotteries are demanded only by those with no gap. If in fact nontrivial employment lotteries are rarely (if ever) observed, then employment lotteries are not only analytically convenient, but their use the (IN) model also fits the facts.

The transfers resulting from the (IN) model's trade in tastes insurance are greater than measure zero. Assessing the empirical relevance of this prediction raises two questions:

- How much "tastes insurance" is observed in fact?

- What is the quantitative importance of tastes insurance in the (IN) model?

In order to answer these questions, one needs to interpret heterogeneity of the marginal disutility of work - remember that "tastes insurance" is the net lifetime transfer from workers who, especially when the wage is high, happen to have low reservation wages to nonworkers who happen to have high reservation wages. "Real world" counterparts to these nonworkers might be women, the sick, or the disabled. Or they might be a generation of men who were unlucky enough to have a low reservation wage when wages were low and a high reservation wage when it was high (e.g., the generation of men of working age during the Great Depression and of retirement age after World War II). "Real world" counterparts to the "tastes insurance" therefore include the sharing of resources

${ }^{8}$ That the date zero trade in consumption insurance eliminates the demand for nontrivial lotteries $(\pi \in(0,1))$ in later periods is shown by Cole and Prescott $(1997)$. 
by husbands and wives, ${ }^{9}$ sick pay, disability insurance, and intergenerational transfers (both public and private), respectively. Such transfers are easily a couple of percentage points of GDP in industrialized countries. In some of these examples, it can even be argued that the real world transfers equalize consumption between payer and recipient - as the transfers literally do in the (IN) model. ${ }^{10}$

There are probably good empirical examples of consumption that varies with the reservation wage in a way that is technically at odds with the (IN) model's predictions. But models are by definition an approximation of "reality," so the real question is not whether differences between observed transfers and the model's taste insurance are literally zero but whether these differences are quantitatively important and whether they are robust to otherwise innocuous modeling changes. On the second point, my Appendix I shows how allowing for nonseparable utility can reduce the magnitude of (IN) model tastes insurance, without sacrificing two key results derived from the separable case: that (a) aggregate labor supply is the same as in an otherwise equivalent (LR) model and (b) the aggregate supply curve takes its shape from a cumulative distribution function.

On the first point, suppose for the sake of argument that we observe literally no transfers from those with low reservation wages to those with high reservation wages. How would the analysis the Frisch labor supply curve in particular - be different if transfers in the model were restricted to be literally zero? Appendix II shows how the aggregate labor supply curve takes its shape from the distribution of reservation wages regardless of whether there is trade in tastes insurance. What simplifies the analysis with tastes insurance is that the shape of the cross-sectional distribution of log reservation wages is "exogenous," taking its shape only from the cumulative distribution function $F$. The reservation wage distribution departs from $F$ without tastes insurance, and the magnitude of the departure depends on the number of periods in a lifetime $(T)$, the degree to which the marginal utility of consumption diminishes, and the individual-level serial correlation of labor force status. The Appendix calculates the magnitude of this difference for some interesting life cycle examples, and suggests that it is quantitatively unimportant.

In other words, an indivisible economy without tastes insurance and populated by life cycle

${ }^{9}$ I owe this point to Yona Rubenstein.

${ }^{10}$ Eg., Mulligan and Sala-i-Martin (1999) look at some recent American and French data suggesting that Social Security equalizes the consumption of workers and retirees in those two countries. 
savers can generate similar, although not identical, aggregate data to a similarly parameterized (LR) model. This result is not surprising, since labor supply is not all that "indivisible" in a life cycle context. The smallest labor supply decision has an infinitesimal effect on lifetime consumption and the marginal utility of wealth in the (LR) model, and a small-but-larger-than-infinitesimal effect on the marginal utility of wealth in the (IN) model - as long as the effect on lifetime consumption (namely, $e^{-\rho(t-1)} Q_{t} w_{t}$ ) is a small of lifetime income $o r$ the marginal utility of wealth does not diminish too rapidly.

\section{III.C. Other Dimensions of Heterogeneity}

Everyone in the Hansen (1985) and Rogerson (1988) economies has their "reservation wage" (i.e., their marginal value of nonmarket time) exactly equal to their market wage. My (IN) model generalizes that case to allow reservation wages to differ from market wages, and as a result implies inelastic aggregate labor supply whenever the distribution of reservation wages is not particularly dense in the neighborhood of market wages. But notice that preference heterogeneity is neither necessary nor sufficient ${ }^{11}$ to derive such an implication. For example, preferences could be homogeneous across persons and over time but the aggregate labor curve be smooth as a consequence of heterogeneity across persons of market labor productivity. A variety of two sector labor market models in the literature have this feature ${ }^{12}$ - such as Roy's (1951) model or Heckman and Sedlacek's (1985) extension of that model. However, interpreting labor supply functions in Roy models is complicated (consider, for example, the combination of the $2^{\text {nd }}$ equation on Heckman and Sedlacek's p. 1081 with their $1^{\text {st }}$ equation on p. 1082), even though heterogeneity is normally distributed, and the models exclude life cycle components. Cho's (1995) simulation results also suggest that smooth labor supply in the presence of indivisible labor might result from wage

${ }^{11}$ To see that preference heterogeneity is not sufficient produce a nondegenerate joint distribution of market and reservation wages, consider a special case in which persons have different tastes and labor productivity in such a way that the two are perfectly correlated (I owe this point to an anonymous referee). Or consider a one period special case of my (IN) model without taste insurance (i.e., a model like Rogerson's (1988, p. 14) example), for which the distribution of tastes is homogeneous enough that everyone demands nontrivial lotteries.

${ }^{12}$ At least if we depart from the original interpretations of these models, and think of one sector as the market sector and the other sector as the nonmarket or leisure sector. 
heterogeneity in a dynamic economy, although he considers only temporary heterogeneity and does not show whether or not similar indivisible and divisible models can be distinguished with aggregate data. Mulligan (2000) has a life cycle model with wage heterogeneity and indivisible labor and, by allowing for trade in contingent claims, derives a set of results analogous to those derived here. Namely it can still be shown that, with heterogeneous labor productivity and indivisible labor, labor market aggregates can be interpreted as if they were generated by an otherwise similar divisible and homogeneous model and that the aggregate Frisch labor supply function is a simple transformation of the productivity-CDF from the heterogeneous economy.

My basic analytical result is that any aggregate data generated from a model with micro-level indivisibilities can be generated from an otherwise similar divisible model, and vice versa. Up to this point, I have proven the result in an indivisible model with only one dimension of heterogeneity namely, the preference parameter dictating the marginal disutility of work. But my result can be derived from models with a variety of dimensions of heterogeneity. To see this, consider the new Assumption (A7):

(A7) In both the (LR) and (IN) economies, there are a continuum of individuals who differ according to their life cycle wage profile $W=\left\{w_{1}, w_{2}, \ldots, w_{T}\right\} \in \mathbb{R}_{+}{ }^{\mathrm{T}}$ and their initial assets $a . G(a, W)$ denotes the joint distribution of those characteristics. For simplicity, these differences are known to individuals prior to the trade in "tastes insurance" specified in (A6) and, in the (IN) model, $G$ is independent of the distribution of tastes $F$.

With Assumption (A7), and adjusting Assumption (A5) to eliminate the word "only," parameterizations of the (LR) and (IN) models are now $\left(a, \rho, n_{\max },\left\{w_{t} g_{t} Q_{t}\right\}, G\right)$ and $\left(a, \rho, \bar{n},\left\{w_{p} g_{p} Q_{t}\right\}, G\right)$, respectively; the parameterizations include functions describing the distribution of wages and assets. We now have Proposition 5:

Proposition 5 The data on aggregate hours and earnings generated by any parameterization of the (LR) model aggregated across individuals according to (A7) are identical to data on aggregate hours and earnings obtained by aggregating some parameterization of the (IN) model across individuals according to (A5), (A6), and (A7). 
Proof (i) Choose any feasible set of parameters $\left(a, \rho, n_{\max },\left\{w_{t} g_{t}, Q_{t}\right\}, G\right)$ for the problem (LR).

(ii) For each group of individuals with the same $(a, W)$, apply the proof of Proposition 2.

(iii) Choose the same distribution $G$ for the (IN) model as for the (LR) model, and obtain aggregates for both models by integrating across groups using the distribution $G$.

I leave it to the reader to prove that the converse of Proposition 5 is also true, and that Proposition 5 can be generalized to allow for other dimensions of heterogeneity, including some taste heterogeneity that is revealed prior to trade in tastes insurance.

In words, similar indivisible and divisible economies generate the same aggregate data even when there is heterogeneity in a variety of dimensions other than the disutility of work, as long as this additional heterogeneity is the same in the divisible and indivisible economies. In this case, the date $t$ Frisch labor supply function for the group of people with the same marginal utility of wealth and the same date $t$ wage takes its shape from the CDF for tastes, $F$. What is no longer necessarily true in this case is that prices and quantities aggregated across groups appear as if they were generated by a representative agent. But this paper does not claim a representative agent always exists, only that indivisible and divisible economies are indistinguishable with aggregate data. Moreover, while the nonexistence of a representative agent may complicate the interpretation of economic aggregates (problems which are the basis of criticisms of aggregate studies by Smith (1977, p. 249) and Pencavel (1986, p. 34)), aggregation may also simplify the interpretation because the aggregates can be understood without regard for micro-level discontinuities. ${ }^{13}$

\section{III.D. Aggregate Studies of Employment have a Simple Microeconomic Interpretation}

Some of the most well known empirical studies of labor are studies of aggregates, such as Mincer's (1962) intercity and time series studies of female labor force participation, Bowen and Finegan's (1969) intercity and other aggregate studies of labor force participation by various demographic groups, and Lucas and Rapping's (1969) study of national employment over time. These and many other studies look at the covariance over time, across cities, or across demographic groups between a group's employment or participation rate, and proxies for that group's earnings

\footnotetext{
${ }^{13}$ I emphasize the benefits of aggregation of micro-level discontinuities. See Grunfeld and Griliches (1960) for examples of potential benefits of aggregating micro-level specification errors.
} 
potential, nonlabor income, household situation, etc. How can the aggregate studies be interpreted? Their authors often interpret the aggregates in terms of microeconomics' basic consumer theory as if they were "chosen" by a single consumer operating in a convex environment - and view the various control variables as proxies for the wage rate and the marginal utility of wealth. Ben Porath (1973), Heckman (1978), and others question such an interpretation on the grounds that first order conditions emphasized by the convex consumer theory cannot be expected to hold at the individual level and that, as a consequence, aggregate labor supply is necessarily a complicated function of individual behavior and heterogeneity.

Ben Porath (1973), Heckman (1978), and Mincer and Ofek (1979) all raise the possibility that an individual's employment decision might indeed be an "intensive" one when viewed in a lifetime context, although they disagree about the empirical relevance of such an interpretation. The debate among these authors revolves around the magnitude of a person's lifetime serial correlation of tastes and/or employment status. But notice that, in my aggregation of (IN), I assume nothing about the serial correlation of an individual's marginal disutility of work $\gamma$. I assume for convenience that the distribution of $\gamma$ across persons is the same every period (up to an aggregate shifter of the geometric mean $g_{t}$ ), but this could result from each individual's drawing a single deviation from the population mean for his entire lifetime, from many independent draws for each individual, or draws that are imperfectly serially correlated over time for each individual. Formally, the difference between my result, Ben-Porath's, and Heckman's, is that Ben-Porath and Heckman do not allow for "tastes insurance," employment lotteries, or a constant marginal utility of wealth $U^{\prime}$. Taken literally, my approach views the employment decision not only in a life cycle context, but also in an extended household context - I cite sick pay, Social Security, and spousal resource sharing as examples of the so-called taste insurance in the model.

The fact that my Propositions 1-2 are consistent with any serial correlation of tastes means that Mincer's (1962) use of a divisible model to interpret his empirical studies of employment rates is consistent with a more general class of life cycle behaviors than Mincer initially supposed, as long as the utility function of a group's "representative agent" is interpreted in terms of within-group taste heterogeneity rather than as a replicate of one person's utility function. In other words, aggregate labor supply equates "the" marginal value of time with the wage rate and, because of the trade in securities among consumers, that marginal value of time is a stable function of a few aggregate 
variables such as aggregate consumption and the employment rate. But unlike an economy of identical individuals making choices on the intensive margin, my (IN) model does not suggest that "the" value of time can be read off of the indifference map of one consumer, but rather is the rate of substitution in utility for the worker indifferent between working or not - a worker whose identity changes over time!

Without taking literally its extended household interpretation, my model still offers some support for Mincer's interpretation of the aggregate studies because its so-called "taste insurance" is mainly an analytical convenience. I demonstrate above and in Appendix II how the divisible model of the employment rate can well approximate aggregate behavior in a model, without "tastes insurance," of micro level discrete choices. My demonstration again revives Ben Porath's (1973, p. 700) quantitative question of the magnitude of a person's lifetime serial correlation of tastes and/or employment status, but I obtain two additional results. First, the serial correlation of employment status is less relevant, in terms of creating a gap between labor supply curves with and without tastes insurance, the less steep is the marginal utility of wealth schedule. Second, even with a reasonable magnitude of the serial correlation, labor supply with tastes insurance may closely approximate labor supply without it.

My (IN) model, and thereby my interpretation of the (LR) model, are not without implications for micro data. To see some of these implications, consider the contrast between my (IN) model and Hansen's (1985) indivisible labor model. Hansen describes aggregate fluctuations as infinitesimal movements along a perfectly elastic labor supply curve, and the identities of workers are unpredictable ex ante. The (IN) model has employment fluctuations as discrete movements along an imperfectly elastic supply curve, with each agent almost surely strictly preferring his chosen labor force status to the alternative. And it takes a larger wage change to alter the decision of a person whose reservation wage is further from the market wage. While Hansen (1985) cannot name who will work as a function of the equilibrium wage, I predict that (to the extent that we can infer reservation wages independently of observing labor market status) the elderly, children, married mothers of young children, and others with date $t$ reservation wages higher than their "normal" date $t$ market wage will not work unless the date $t$ market wage is substantially higher than what is "normal" for them. Indeed, the elderly, children, and (although much less so in recent years) married mothers of young children typically do not work except in extreme circumstances such as wartime 
(Mulligan 1998b).

Hansen's (1985) paper also revisits the question of how to calibrate macro models in a way that is consistent with microeconomic observations (in particular, observations that not all labor supply is in the so-called "intensive" margin). Considering the various dimensions of this question is beyond the scope of this paper - Hansen and Heckman (1996) are among those papers offering more comprehensive answers - but my results offer some simple answers to this question. Namely, if the indivisible model is right, then there are in principal two ways to calibrate labor supply elasticities for the LR model: (1) estimate the distribution of tastes or (2) look at the covariance between aggregate manhours and aggregate earnings using data where wage variation is arguably independent of wealth effects and other sources of manhours variation. Method (1) probably begs the question, but method (2) may be practical. Method (2) is essentially the approach of Mincer's famous 1962 study, which looks at female labor force participation and earnings across cities to calibrate a time series model of national female labor force participation. It is also the approach of Mulligan (1998a) who suggests looking at earnings and aggregate manhours (a.k.a., the product of the "employment rate" and "hours per employee") across groups defined by their year of birth - rather than restricting the analysis to hours among employees as in Ghez and Becker (1975) or by following continuously-employed individuals over time as in MaCurdy (1981) - in order to calibrate LR-type models of national manhours.

\section{III.E. The Logical Possibility of Backward-Bending Aggregate Labor Supply}

Ben-Porath (1973, p. 702) claims that, when labor is supplied on the so-called "extensive" margin, economic theory allows us to sign the relative aggregate wealth and substitution effects of a wage change in a way that is not possible with a divisible model. In other words, his claim is that aggregate labor supply might bend backward when labor is supplied on the intensive margin, but in theory cannot when it is supplied on the extensive margin. The claim is familiar to students of labor economics, and is implicitly strengthened by Hansen (1985) and Rogerson (1988) who suggest that aggregate wealth and substitution effects are like those from a quasilinear utility model (i.e., the LR model with $v(N)$ linear in $N$ ).

My Proposition 2 shows how aggregate data generated by any parameterization of a divisible model - including those for which aggregate labor supply bends backwards - can be generated by an 
indivisible model (a.k.a., a model for which all labor is supplied on the extensive margin). It follows that Ben-Porath's claim is incorrect, or at least incorrectly applied to aggregate studies like Mincer's, because Ben-Porath assumes that an aggregate wage change has no effect on the distribution of nonlabor income. In other words, Ben-Porath can sign the relative wealth and substitution effects not from hypotheses about the indivisibility of labor, but from hypotheses about (1) the pooling of earnings over time and across people and (2) what is the meaning of a "wage change." To see this, consider three simple illustrations that show how the indivisibility of labor is neither necessary nor sufficient to rule out backward bending labor supply. First, suppose that we have a continuous time model of finite duration (e.g., one year). Wages are initially constant over time, and the same across persons. Tastes vary over time and across persons, in such a way that everyone works at least some amount of time, and takes leisure some amount of time. Hence, any labor supply in this economy is on the "intensive" margin. Now consider an across-the-board wage increase at some point in time $t$ (e.g., December 25th) that is marginal for at least some people and inframarginal for nobody. If the pooling of earnings over time and across persons is limited enough, then we have a Ben-Porath type result even though all labor is supplied on the "intensive" margin: aggregate labor supply must in theory increase because the additional date $t$ earnings of some people cannot be used to finance leisure time at some other date $s$ (e.g., in January) for those people with increased earnings, or for others. $^{14}$

As a second example, consider a one period economy with indivisible labor and wages that are the same for everyone in the economy. Tastes are different, so some people work and others do not. If we increase wages across-the-board and people are sufficiently sharing their earnings, then aggregate employment can fall, depending on the rate at which the marginal utility of wealth declines with wealth - this is just an application of my Proposition 2 with $T=1$.

To make this second example more concrete, consider the application of most interest to Mincer (1962) and Ben-Porath (1973) - interpreting cross-city differences in the labor force participation of women. For simplicity, let's suppose that each city is its own one-period economy as described above, with each city having the same within-city distribution of tastes. Wages can differ

\footnotetext{
${ }^{14}$ Yet another "intensive margin" example for which the substitution effect may be expected to dominate the wealth effect of a wage change occurs when in life cycle models when wage changes (e.g., Ghez and Becker 1975).
} 
across cities, but only for half of the residents - the women (i.e., men have the same wage in every city). Do women work more or less in the cities with high female wages? They can work less, if some women are pooling earnings with other women. For example, middle aged women may work in every city, but only the high female wage cities can "afford to" let elderly women be retired.

As a third example, consider a two period economy with indivisible labor, and wages the same over time and across persons. Tastes differ across persons and over time. Individuals do not directly share resources with each other, but they can borrow and lend. In order to have some consumption, people therefore work at least one period; the interesting labor supply question is who works two periods rather than one. If we increase wages for all persons and all time periods, then aggregate employment can fall, depending on the rate at which the marginal utility of wealth declines with wealth. In layman's terms, it is possible that the effect of a higher wage is that more people can afford to retire (i.e., work one period rather than two).

Returning to the application to cross-city female employment, the third example implies that cities with the highest female wages may have the lower employment rates because women in those cities use their extra wage income to save for retirement. This third example is related to Heckman's (1978, p. 205) discussion of labor force participation over the life cycle, but comparing it with my second example shows that it is the sharing of resources in one form or another, and not life-cycle savings per se, that allows employment rates to "bend backwards." Of course, my examples do not suggest that aggregate labor supply must bend backward in either the (LR) or (IN) models, only that such an observation cannot be used to determine whether labor is supplied on the "extensive" or "intensive" margin.

\section{Two Generalizations of the Indivisible Model}

My results leave open the possibility that generalizations of the indivisible model might have aggregate implications. One approach is to modify the two models so that they generate aggregate data on earnings, employment rates, and hours per employee. I do so in Section IV.A, introducing "hours" margins into the indivisible model by time-aggregating individual-level choices on the "extensive" margin. A second generalization of the indivisible model features government policies 
that are affected by the indivisibility of labor. ${ }^{15}$

\section{IV.A. "Intensive” and "Extensive” Margins in Divisible and Indivisible Economies}

Labor supply is almost always measured as a time aggregate: the total time worked during a particular time interval such as a day, week, or year. My Section II follows the previous literature and presumes that the time interval over which labor is indivisible coincides with the interval of time aggregation. That is, if labor supply is measured by calendar month, then the calendar month is the time interval during which labor supply must be either 0 or $\bar{n}$. By relaxing that assumption, we can modify the model (IN) so it generates time-aggregated aggregate data that appears to have "intensive" and "extensive" margins.

Let the "measurement period" be an aggregate of $K$ periods (or "potential work sessions") in the model (IN). Work sessions are indexed $t=1, \ldots, T K$ and measurement periods $j=1, \ldots, T$. Thus $j=1$ denotes an aggregate of sessions $t=1, \ldots, K ; j=2$ denotes an aggregate of sessions $t=$ $K+1, \ldots, 2 K$, etc. As an example, if the potential work session were a month and adult life span equal to 50 years, then $K=12$ and $T=50$ would model the Census Bureau's annual measures of labor supply.

A person is said to be "employed" during measurement period $j$ if positive hours are worked during any of the sessions $t=(j-1) K+1, \ldots, j K$. Since $n_{t} \in\{0, \bar{n} / K\}$ for $t=1, \ldots, T K$, an individual's measured labor supply must be from the set $\{0, \bar{n} / K, 2 \bar{n} / K, 3 \bar{n} / K, \ldots, \bar{n}\} .{ }^{16}$ Assuming that the wage rate $Q_{t} w_{t}$, the degree of indivisibility $\bar{n} / K$, and the geometric average marginal disutility of work parameter $g_{t}$ are constant throughout the measurement period, then the fraction of people "employed" during the measurement period $j$ is:

\footnotetext{
${ }^{15}$ Two other generalizations are explored by Mulligan (1999). The first allows
} heterogeneity in the degree of indivisibility $\bar{n}$, and second explicitly models the labor indivisibility, and hence why $\bar{n}$ might vary across persons. In some cases, there is data on aggregate hours, employment, and earnings that can be generated by divisible models of intensive and extensive margins (such as (LR)' below), but not by the indivisible models. However, these aggregate implications are rather subtle, especially when the process determining $\bar{n}$ varies across workers, and the parameters of that process are unobserved.

${ }^{16}$ To facilitate the comparison with the time-disaggregated models, the degree of indivisibility is expressed in units such that the maximum labor supply during the measurement period is $\bar{n}$. 


$$
\Pi_{j}=1-\left[1-F\left(\ln \frac{w_{j} Q_{j} \lambda}{g_{j}}\right)\right]^{K}
$$

As in the time disaggregated model, aggregate hours measured for period $j$ are:

$$
N_{j}=F\left(\ln \frac{w_{j} Q_{j} \lambda}{g_{j}}\right) \bar{n}
$$

"Hours per employee" for measurement period $j$ can then be calculated as the ratio $N / \Pi_{j}$. In words, time-aggregating the (IN) model produces a model for which "employment" and "hours" are meaningful statistical distinctions, even if they are not meaningful economic distinctions.

How do employment and hours from the indivisible economy compare with employment and hours from a divisible economy? To answer this, I follow Hanoch (1980), Kydland and Prescott (1991), Cho and Cooley (1994), and others to generalize the divisible (LR) model to have both "extensive" and "intensive" margins. This generalization is denoted (LR)', and has the marginal disutility of work depending separately on the employment rate $\Pi$ and hours conditional on employment $n$ :

\section{(LR)' Divisible Labor with "Intensive" and "Extensive” Margins}

$$
\begin{gathered}
\max _{C,\left\{\Pi_{j}, n_{j}\right\}_{t=1}^{T}} U(C)-\sum_{j=1}^{T} e^{-\rho(j-1)} g_{t} v\left(\Pi_{t}, n_{t}\right) \\
\text { s.t. } \Pi_{j} \in[0,1] \quad, \quad n_{j} \in\left[0, n_{\max }\right] \\
C=a+\sum_{j=1}^{T} e^{-\rho(j-1)} Q_{j} w_{j} \Pi_{j} n_{j}
\end{gathered}
$$

The only difference between (LR) and (LR)' is that (LR)' makes predictions for the decomposition of each date's aggregate hours $N_{j}$ into an employment rate $\Pi_{j}$ and hours conditional on employment $n_{j}$. In particular, optimal $\Pi_{j}$ and $n_{j}$ are time-invariant functions of $N_{j}$. I interpret (LR) ${ }^{\prime}$ as an 
aggregation across persons (as with (LR)) and as an aggregation of work sessions within a measurement period (hence, the $j$ indices in $\left.(\mathrm{LR})^{\prime}\right)$. Hanoch (1980) considers (LR)' with $T=1$ and interprets it as a time-aggregated model of individual-level decisions. In his interpretation, $\Pi_{j}$ is the fraction of the 52 weeks in year $j$ during which some work occurs and $n_{j}$ is average hours worked during those $52 * \Pi_{j}$ weeks.

This time aggregation of (IN) produces a special case of the divisible model (LR) ${ }^{\prime}$. In particular, it is the special case with utility function:

$$
v(\Pi, n)=\hat{v}\left(\ln \left(\frac{n}{\bar{n}}-\frac{1}{K}\right)+\lim _{z \rightarrow 0} \int_{z}^{\Pi} \frac{1}{x} \frac{1-(1-x)^{1 / K}}{1-(1-x)^{1 / K}-x / K} d x\right)
$$

with $\hat{v}(\cdot)$ an increasing function (a transformation of the CDF F). Equations (4)-(6) reveal four common implications of (LR) ${ }^{\prime}$ and the time-aggregated indivisible models with $K>1$. First, equation (6) need not be linear in $\Pi$ or $n,{ }^{17}$ so that both models are consistent with wage inelastic employment and hours. Second, since both models have upward sloping aggregate Frisch supply curves for employment and hours, and both define "employment" and "hours" so that their product is aggregate hours, both imply that the wage elasticity of aggregate hours must exceed both the wage elasticity of employment and the wage elasticity of hours per employee.

Third, either model can have aggregate (Marshallian) hours and employment supply curves that bend backwards. To see this for the (IN) model (with $K>1$ ), combine equations (4) and (5) to eliminate $F$ and calculate average hours $n$ per person employed during the measurement period $j$ :

$$
n_{j}=\bar{n} \frac{1-\left(1-\Pi_{j}\right)^{1 / K}}{\Pi_{j}}
$$

${ }^{17}$ Cho and Cooley (1994, p. 241) also note the connection between a divisible model of intensive and extensive margins and a time-aggregated indivisible model. Since they consider only the case of homogeneous reservation wages, they find the time-aggregated indivisible model to be isomorphic with a special case of $(\mathrm{LR})^{\prime}$ - one with disutility linear in $\Pi$. 
Like the model (LR)', there is a time-invariant monotonic relationship between employment, hours per employee, and aggregate hours in the time-aggregated (IN) model. Since the aggregate (Marshallian) supply of aggregate hours can bend back in either model, this implies that employment rates and average hours per employee can bend backward in both models. Fourth, both models can have more labor supplied on the "extensive" margin, or more on the "intensive" margin, depending on the model parameters. Equation (7) shows how the former occurs in the (IN) model when $K$ or $N$ are small, and how the latter occurs when $K$ or $N$ are large.

There is some behavior inconsistent with indivisible labor (i.e., inconsistent with the disutility function (6)). Not surprisingly, equation (7) requires that hours per employee $n$ be no less less than $\bar{n} / K$ in the indivisible model. Perhaps more importantly, hours per employee $n$ tends to be less wage sensitive at low employment rates and more wage sensitive at high employment rates.

The time-disaggregated model (IN) has a rather trivial Frisch labor supply curve for each individual - namely, a single-step function with the step occurring when the market wage equals the reservation wage (with both consistently adjusted for discounting). As compared with the aggregate labor supply curve, the individual's curve is less elastic at any any wage not equal to his reservation wage, and more elastic at the reservation wage. Individual labor supply for the measurement period is more interesting when the (IN) model is time-aggregated as suggested above - namely, a multiplestep function with each step occuring when the market wage equals one of the $K$ reservation wages for the measurement period. The individual's curve is therefore reflects his own distribution of reservation wages (see also Lucas 1970, p. 25), while the aggregate curve reflects the cross-sectional distribution $F$. Hence, the conceptual distinction between cumulative distribution functions and individual labor supply curves is more blurry than even suggested by my Propositions 1 and 2 .

\section{IV.B Time-Aggregated Nonlinear Tax Rules}

We might expect government policy to have different effects on aggregate labor and consumption in the (LR) and (IN) models, at least when those policies are distortionary and sufficiently nonlinear. To see this, consider the introduction of a simple government sector. A dictator levies labor income taxes on each citizen according to his earnings for the accounting period, consumes the revenue, and otherwise has no other contact with consumers. For simplicity, let the government accounting period (a "year") be equal to the time interval during which labor is 
indivisible, namely 1 . Let $\tau_{t}\left(e_{t}\right)$ denote the tax schedule, namely, the mapping from a person's period $t$ earnings $e_{t}$ to his period $t$ tax liability. Let $\tau_{t}^{\prime}\left(e_{t}\right)$ denote the marginal tax rate (i.e., the derivative of the function $\left.\tau_{t}(\cdot)\right)$ and $\bar{\tau}_{t}(e) \equiv \frac{\tau_{t}(e)-\tau_{t}(0)}{e}$ the "average tax rate."

Of course, when facing such a government, the representative consumer from the divisible economy equates his date $t$ marginal rate of substitution to the after-marginal-tax wage, $w_{t}\left[1-\tau_{t}{ }^{\prime}\left(N_{t} w_{t}\right)\right]$, because he is concerned with the marginal effect of work on consumption. The marginal worker in the indivisible economy, however, has marginal rate of substitution equal to the after-average-tax wage $w_{t}\left[1-\bar{\tau}_{t}\left(\bar{n} w_{t}\right)\right]$, because he is concerned with the effect of the smallest change in work on his consumption. If tax schedules are linear - even if they vary over time - average and marginal tax rates are the same at any point in time and behavior is the same in the divisible and indivisible economies as long as the other conditions of Propositions 1 and 2 hold. If tax schedules are nonlinear, then average and marginal tax rates are different, ${ }^{18}$ and behavior in divisible and indivisible economies is different even when both economies have the same parameters and the same tax schedules.

This behavior has significant relevance for public finance. For example, it has been extensively argued (e.g., Hall and Rabushka 1995) that a revenue neutral flat tax would dramatically increase the efficiency of taxpayers' time allocations. But, of course, this analysis relies heavily on the presumption that - holding constant tax revenue - labor supply depends on the marginal tax rate. My simple model suggests that perhaps only the average tax rate matters in a model of indivisible labor when the "indivisibility" is at least as long as the tax accounting period. Second, the distinction between average and marginal tax rates matters for the estimation of labor supply elasticities (which are used for, among other things, tax reform simulations). As argued above for the indivisible model, the observations of MaCurdy (1992) and others that micro or aggregate labor supply is unresponsive to marginal tax rates is quite consistent with wage-elastic aggregate labor supply. Hoynes (1996), Leibman and Eissa (1996), and Mulligan (1998a) study applications of this result, suggesting that average rather than marginal tax rates explain labor supply.

${ }^{18}$ See Barro and Sahasakul 1983 for a demonstration that they have been quite different for the U.S. personal income tax 
This reasoning suggests another potential difference between divisible and indivisible labor models: in a population of heterogeneous individuals facing the same labor income tax schedule, the former predicts that the cross-sectional distribution of a year $t$ 's earnings has mass points at any "kink" in the tax schedule, whereas the mass points in the indivisible model are at 0 and $w_{t} \bar{n}_{t}$. Unless the degree of indivisibility $\bar{n}$ itself responds to tax incentives, $w_{t} \bar{n}_{t}$ does not necessarily coincide with any kinks in the tax schedule even if the distribution of tastes is equal enough that aggregate labor supply is quite elastic. Thus the findings of Hausman (1986) and others that the income distribution does not seem to be concentrated at kinks in the individual income tax schedule, might be expected when labor is indivisible, and is consistent with large wage elasticities of aggregate labor supply.

Some features of my simple indivisible labor model of government policy are quite crucial, even though at first glance they appear innocuous. For example, it is crucial that the nonlinear tax is on labor rather than consumption because while a person's labor income is indivisible, his consumption is not because he pools his earnings over time, and is sharing some earnings with others via lotteries and tastes insurance. Hence, even nonlinear consumption taxes have the same implications for divisible and indivisible models. It is also crucial that my model of taxes does not allow the pooling of earnings over time or across persons for tax purposes, even while such pooling occurs for the purpose of financing consumption expenditure. If pooling across persons did occur for tax purposes, and the tax schedule was globally weakly convex, then everyone would have the same date $t$ taxable earnings (even those not working!) equal to $N_{t} w_{t}$ and the same marginal tax rate - just as in the divisible model. ${ }^{19}$ Since a rigorous analysis of indivisible labor and taxable income pooling, let alone interpreting such trades in terms of "real world" transactions, is well beyond the scope of this paper, I leave this to future research and leave here only the caveat that there are some conditions under which divisible and indivisible economies generate the same aggregate data even when labor income tax schedules are nonlinear.

\section{Conclusions}

I follow a number of previous studies (e.g., Diamond and Mirrlees (1978, 1986), Hansen

\footnotetext{
${ }^{19}$ The pooling of nontaxable income does not have to be complete in order to obtain equivalence between divisible and indivisible models - it can occur in many separate small groups, such as the groups pooling earnings in the economy of Proposition 5.
} 
(1985), Hamilton (1988), Christiano and Eichenbaum (1992)) and model the micro-level "indivisibility" of labor in a life cycle context. Namely, a lifetime is divided into time intervals and during each of those intervals work must occur for exactly $\bar{n}$ units of time or there be no work at all. This indivisible environment is contrasted with the "divisible" labor environment described by Lucas and Rapping (1969). Mathematically, and perhaps also economically, the indivisible model has clear implications for individual-level observations of labor market activity. These micro implications have been studied extensively in previous literatures and include, for example, the likely possibility that an individual's marginal value of nonmarket time is not equal to his market wage. But what are the implications of such indivisibilities for aggregate market data?

I suggest that the micro-level indivisibility of labor, as modeled in the literature, has no implications for aggregate labor market data, at least in the absence of nonlinear labor income taxes. More precisely, I show how any data on aggregate hours and earnings generated by my model of micro-level indivisible labor can be generated by an otherwise similar divisible labor model, and vice versa. For example, micro-level indivisible labor is consistent with the same variety of Frisch labor supply functions that can be derived from divisible models, and hence with the same variety of wealth and substitution effects that are feasible in divisible models.

The proof of the equivalence of divisible and indivisible models is interesting and relevant for interpreting aggregate studies of the labor market. It shows how group labor supply can be interpreted as if chosen by a group representative who cares about average group consumption and work, thereby equating the group's market wage to "the" nonmarket value of time, even though nearly all of the group's members have a personal nonmarket value of time that differs from the market wage. The "utility function" of a group's "representative" is interpreted in terms of withingroup taste heterogeneity rather than as a replicate of any one person's utility function. The group's date $t$ nonmarket value of time cannot be read from the indifference map of a particular consumer, but rather is the rate of substitution in utility for whichever worker happens to be indifferent between working or not at date $t-$ a worker whose identity changes over time. This group nonmarket value of time is not an unpredictable variable, but rather a stable monotonic function of group consumption and work hours, just as an individual's nonmarket value of time is a stable monotonic function of his consumption and work hours in divisible models of individual labor supply. The "stable monotonic function" derives from the cross-sectional $C D F$ for tastes in the former case, and from an individual's 
disutility of work function in the latter case.

Indivisible models can be used to derive separate implications for "employment" and "hours" by time-aggregating individual-level choices on the "extensive" margin to obtain aggregate and individual-level measures of "employment" and "hours." Such a model is consistent with any nonnegative Frisch wage elasticity of aggregate employment and hours, and consistent with backward-bending Marshallian supply curves for aggregate employment and hours. Depending on the model parameters, more labor can be supplied on the employment margin, or more can be supplied on the hours margin. Furthermore, the time-aggregated model further blurs the distinction between divisible and indivisible models, because even an individual's "disutility of work" schedule can be interpreted in terms of a distribution function for tastes. The time-aggregated indivisible model does require that hours be wage insensitive relative to employment at low employment rates and relatively wage sensitive at high employment rates, a requirement not shared with models of employment and hours built on divisible choices.

Indivisible models may also have aggregate implications when there is some economically significant time aggregation in the economy. One quite interesting case is the almost universal government practice of levying taxes on time aggregates of earnings. Indivisible labor therefore has important implications for public finance, one of which is the relative insensitivity of labor supply to marginal tax rates.

Labor productivity cannot be directly observed when a person is not working. Moreover, a sample of workers is certainly a sample selected according to labor productivity. This paper does not deny these realities. However, a number of authors in the literature have taken this fact a step further, suggesting that studies of the "hours" margin are immune to (or at least less sensitive to) the problem of inferring missing wages than are studies of the "employment" margin. ${ }^{20}$ Their suggestions may be true, but cannot be derived as a matter of logic. Just as we do not know the current labor productivity of a woman who has been out of the labor force for five years, we do not know the summer labor productivity of a school teacher or the late-night labor productivity of a banker who is continuously employed during normal business hours. Since the important econometric problem of inferring labor productivity for those times when a person does not work need not be related to

\footnotetext{
${ }^{20}$ See Heckman (1993) for a clear statement of this claim and a survey of the literature.
} 
the divisibility of labor or to the distinction between "employment" and "hours," I have neglected any discussion of that issue in my attempting to answer the question "What are the Aggregate Implications of Indivisible Labor?"

\section{Appendix I: Individual and Aggregate Labor Supply with Consumption-Leisure Nonseparabilities}

It is easy to show that the two main results from the text can be derived for economies in which each individual's utility fails to be separable in consumption and leisure. Namely, any aggregate data generated by the indivisible economy can be generated by an otherwise similar divisible economy, and the Frisch labor supply function takes its shape from the CDF for tastes. The proof of these claims is more complicated than for the separable case, so my proof is limited to a one period planner economy. I leave it to the reader to verify that the results generalize to many period economies and the planner's chosen allocations can be decentralized via trade in contingent claims.

For the indivisible economy, each individual has utility function $U(c, n ; \gamma)=u(c, n)-\gamma n$. For simplicity I set $\bar{n}=1$, so that only $n \in\{0,1\}$ is feasible for any individual in the indivisible economy. $U$ 's cross derivative is nonzero, so it can model any conceivable nonseparability between $c$ and $n$, subject to the usual restrictions that $c$ is a good, $n$ is a bad, and indifference maps are convex. $\gamma>$ 0 is a utility parameter that varies across consumers, with $\ln \gamma \sim F$ as in the main text (except with $g=1$ ). While this specification allows for consumption-leisure nonseparability, and a lot of heterogeneity in marginal disutility of work schedules, all consumers with the same work status $n$ have the same marginal utility of consumption schedule.

All consumers are endowed with assets $a$ and have a market wage rate of $w$, which are known prior to revelation of their taste parameter $\gamma$. They engage in trade in employment lotteries and tastes insurance, maximizing expected utility, so the welfare theorems tell us that the equilibrium allocations for this economy can be calculated as solutions to the utilitarian planner problem below: 


$$
\begin{gathered}
\max _{c(\cdot), n(\cdot)} \int_{x_{1}}^{x_{2}} U\left(c\left(e^{x}\right), n\left(e^{x}\right) ; e^{x}\right) d F(x) \\
\text { s.t. } \quad n(\gamma) \in\{0,1\} \text { for all } \gamma \\
\int_{2}\left[c\left(e^{x}\right)-w n\left(e^{x}\right)\right] d F(x) \leq a
\end{gathered}
$$

I leave it to the reader to verify that a competitive equilibrium implementing the "planner' $\mathrm{s}$ " choices can involve trade in tastes insurance and employment lotteries and that, unlike the employment lotteries in the main text, the allowance paid to lottery participants varies with the outcome of the lottery.

I consider the interesting cases in which the wage rate $w$ and distribution of tastes $F$ are such that at least some people work and at least some people do not work. In these cases, we have:

Proposition A1 The marginal utility of consumption is equalized across persons, while consumption varies according to work status.

Proof The planner's first order condition with respect to $c(\gamma)$ implies that $\partial u / \partial c$ is equalized across persons. Since all persons have the same marginal utility of consumption schedule conditional on work status, work status shifts this schedule, and work status varies across persons, consumption must vary across persons according to their work status.

Proposition A1, together with the fact that consumers are identical in every way except $\gamma$, suggests that the planner will in effect choose a critical $\gamma^{*}$ such that all workers have $\gamma \leq \gamma^{*}$ and all nonworkers have $\gamma>\gamma^{*}$. Defining $N=F\left(\ln \gamma^{*}\right)$ as the aggregate work chosen by the planner, (A-1) becomes a choice problem (A-2) for three scalars $\left(c_{0}, c_{1}, N\right)$ :

$$
\max _{c_{0}, c_{1}, N}\left[\begin{array}{c}
N u\left(c_{1}, 1\right)+(1-N) u\left(c_{0}, 0\right)-\int_{x_{1}}^{F^{-1}(N)} e^{x} d F(x) \\
\text { s.t. } N c_{1}+(1-N) c_{0}-w N \leq a
\end{array}\right]
$$


The planner's problem (A-2) makes it easy to prove the next two propositions:

Proposition A2 Any aggregate consumption $C$ and aggregate work $N$ generated by the indivisible economy (A-1) can be generated by an otherwise similar divisible economy.

Proof It suffices to show that there exists a function $\tilde{U}(C, N)$ such that:

(i) $\quad C, N$ from the indivisible economy with assets $a$ and wage $w$ solve:

$$
\underset{\mathrm{C}, \mathrm{N}}{\operatorname{argmax}} \tilde{U}(C, N) \text { s.t. } \quad C-w N \leq a
$$

(ii) The cross-derivative of $\tilde{U}(C, N)$ has the same sign as the cross-derivative of the indivisible economy's $U(c, n)$.

The characterization (A-2) of the planner's problem for the indivisible economy makes it clear that the following $\tilde{U}(C, N)$ is such a function:

$$
\tilde{U}(C, N) \equiv \max _{c_{0}, c_{1}}\left[N u\left(c_{1}, 1\right)+(1-N) u\left(c_{0}, 0\right)-\int_{x_{1}}^{F^{-1}(N)} e^{x} d F(x)\right]
$$

Proposition A3 The Frisch labor supply curve from the indivisible economy takes its shape from the CDF for tastes, $F$.

Proof (i) Let $\lambda$ denote the marginal utility of consumption. By definition, the Frisch labor supply curve is the function $N(\lambda, w)$ implicitly defined by the system of first order conditions from (A-2):

$$
\begin{gathered}
\frac{\partial u}{\partial c}\left(c_{1}, 1\right)=\lambda=\frac{\partial u}{\partial c}\left(c_{0}, 0\right) \\
\ln \left[u\left(c_{1}, 1\right)-\lambda c_{1}-u\left(c_{0}, 0\right)+\lambda c_{0}+\lambda w\right]=F^{-1}(N(\lambda, w))
\end{gathered}
$$

(ii) Inverting the first order condition with respect to $N$, we have a closed form solution for the Frisch 
labor supply curve:

$$
\begin{gathered}
N(\lambda, w)=F(\ln [\Delta(\lambda)+\lambda w]) \\
\Delta(\lambda) \equiv u\left(c_{1}(\lambda, w), 1\right)-\lambda c_{1}(\lambda, w)-u\left(c_{0}(\lambda, w), 0\right)+\lambda c_{0}(\lambda, w)
\end{gathered}
$$

(iii) Note that $\Delta(\lambda)$ is independent of $w$, and is zero when utility is separable. Hence the Frisch relation between $N$ and $w$ for a given $\lambda$ takes its shape only from the CDF $F$.

Propositions A2 and A3 show that indivisible economies still look like divisible economies, even when utility is not separable in consumption and leisure. Furthermore, nonseparable indivisible economies can have elastic, or quite inelastic, aggregate Frisch labor supply curves. The aggregate wealth effect of a wage change can exceed its substitution effect in nonseparable indivisible economies. However, as I have modeled nonseparability in the indivisible economy, there are some aggregate consumption-leisure interactions that are possible in a divisible economy but not in an indivisible one (eg., Proposition A2 shows how aggregate leisure time must interact linearly with aggregate consumption in my version of the nonseparable indivisible model). I leave it to future research to determine whether generalizations of the indivisible model might widen the scope of possible consumption-leisure interactions.

\section{Appendix II: The Distribution of Reservation Wages without Transfers}

How would the analysis - the Frisch labor supply curve in particular - be different if transfers in the model were restricted to be literally zero? To answer this, consider again the (IN) model's condition for working for person $i$ at date $t$ :

$$
n_{t}^{i}=\left\{\begin{array}{lll}
0 & \text { if } & \gamma_{t}^{i}>Q_{t} w_{t} U^{\prime}\left(c^{i}\right) \\
1 & \text { if } & \gamma_{t}^{i}<Q_{t} w_{t} U^{\prime}\left(c^{i}\right)
\end{array}\right.
$$

Since lifetime consumption is indexed by $i$, this condition applies regardless of whether tastes insurance is traded. And this condition just says that person $i$ works at date $t$ when his date $t$ 
reservation wage $\hat{w}_{t}^{i}$ is less than the wage $w_{t}$ in adjusted present value, where the reservation wage is defined as:

$$
\ln \hat{w}_{t}^{i} \equiv \ln \gamma_{t}^{i}-\ln U^{\prime}\left(c^{i}\right)
$$

In other words, the aggregate labor supply curve takes its shape from the distribution of reservation wages regardless of whether there is trade in tastes insurance. What simplifies the analysis with tastes insurance is that the shape of the cross-sectional distribution of log reservation wages is "exogenous," taking its shape only from the cumulative distribution function $F$ because the marginal utility of wealth is constant in the cross-section. Without tastes insurance in the model, we have to worry about inequality of the marginal utility of wealth $\left(U^{\prime}(c)\right)$ and have to calculate the joint distribution of marginal utility and tastes.

A closed form solution for this joint distribution is not available, but we can analytically characterize the variance of the distribution of log reservation wages for some interesting examples and compare it to the variance of $F$ and thereby make a quantitative comparison of the elasticity of Frisch or "consumption-constant" aggregate ${ }^{21}$ labor supply curves in indivisible economies with and without tastes insurance. Equation (A-3) implies that, without tastes insurance, the standard deviation of date $t$ reservation wages are:

$$
\begin{gathered}
\operatorname{sd}^{2}\left(\ln \hat{w}_{t}^{i}\right)=\operatorname{sd}^{2}\left(\ln \gamma_{t}^{i}\right)+\operatorname{sd}^{2}\left(\ln U^{\prime}\left(c^{i}\right)\right)-2 \operatorname{sd}\left(\ln \gamma_{t}^{i}\right) \operatorname{sd}\left(\ln U^{\prime}\left(c^{i}\right)\right) r \in \\
{\left[\left(\operatorname{sd}\left(\ln \gamma_{t}^{i}\right)-\operatorname{sd}\left(\ln U^{\prime}\left(c^{i}\right)\right)\right)^{2}, \operatorname{sd}^{2}\left(\ln \gamma_{t}^{i}\right)+\operatorname{sd}^{2}\left(\ln U^{\prime}\left(c^{i}\right)\right)\right]}
\end{gathered}
$$

where $\operatorname{sd}(\cdot)$ denotes the cross-section standard deviation, and $r$ is the cross-section correlation

\footnotetext{
${ }^{21}$ Since the marginal utility of wealth varies across persons in the absence of tastes insurance, more needs to be said about the definition of "Frisch" aggregate labor supply in such economies. Let date $t$ Frisch aggregate labor supply be the graph of aggregate work versus $\ln w_{t}$, holding aggregate lifetime consumption $C$ constant - a graph which would be literally be interpreted as a Frisch supply curve by someone modeling the aggregates with the (LR) model.
} 
between $\ln \gamma$ and $\ln$ marginal utility of wealth. With tastes insurance, date $t$ reservation wages have standard deviation $\operatorname{sd}(\ln \gamma)$. Equation (A-4) shows that reservation wages can vary more or less when there is tastes insurance, and places bounds on the difference of this variance between economies with and without tastes insurance. The next step is to make a numerical calculation of those bounds for an interesting example.

To make such a numerical calculation, consider a special case of the (IN) environment with finite lifetimes partitioned in $T$ periods, interest and discount rates equal zero, zero initial assets, and a wage $w$ that is constant over the life cycle. Normalize $\bar{n}=1$ and $w \bar{n} T=1$, so that maximum possible lifetime earnings is 1 . The distribution $F$ of $\ln \gamma$ is normal at each date $t$, and let the mean of $F$ be zero so that $N=1 / 2$ in the economy with tastes insurance. Clearly, aggregate work is constant over time regardless of whether there is tastes insurance, and average lifetime consumption $C$ in this economy is equal to average lifetime work $N$.

If effect, tastes insurance contracts in this economy make a transfer in the amount $-1 /(2 T)$ for each period a person has $\gamma \leq 1$ and $+1 /(2 T)$ for each period a person has $\gamma>1$. The cross-sectional distribution of net lifetime transfers therefore depends on the individual-level serial correlation of labor force status. If, for example, there were no serial correlation, then each person's net lifetime transfer would be practically be zero since each person would typically spend half of his life working and half not working. At the other extreme, perfect serial correlation means that half of the population spend all of their life working while the other half do not ever work, and tastes insurance transactions would be large in order to equalize consumption of workers and nonworkers. In order to study intermediate situations, let the lifetime profile of tastes $\Gamma$ be assigned such that ex ante each worker has the same probability of transition into or out of employment in any two adjacent periods, and let $\delta$ denote the fraction of the population making such a transition at any point in time. The cross-sectional standard deviation of net lifetime transfers $P\left(\Gamma_{i}\right)$ is therefore:

$$
\operatorname{sd}\left(P\left(\Gamma^{i}\right)\right)=\frac{\sqrt{T+2 \sum_{t=1}^{T}(T-t)(1-\delta)^{t}}}{2 T}
$$

which, as expected, reduces to practically zero $(1 / \sqrt{T})$ when there is no serial correlation $(\delta=1)$ and 
quite large (equal to aggregate consumption) when there is perfect serial correlation $(\delta=0)$.

Using the fact that the cross-sectional standard deviation of lifetime consumption in the economy without tastes insurance is bounded above by the standard deviation of $P\left(\Gamma_{i}\right),{ }^{22}$ and using a Taylor approximation of the marginal utility of wealth in the neighborhood of $U^{\prime}(C)$, we can compute the cross-sectional standard deviation of log marginal utility of wealth in the economy without tastes insurance:

$$
\operatorname{sd}\left(\ln U^{\prime}\left(c^{i}\right)\right) \approx \frac{-U^{\prime \prime}(C)}{U^{\prime}(C)} \operatorname{sd}\left(c^{i}\right) \leq \frac{-U^{\prime \prime}(C)}{U^{\prime}(C)} \operatorname{sd}\left(P\left(\Gamma^{i}\right)\right)=\sigma \frac{\sqrt{T+2 \sum_{t=1}^{T}(T-t)(1-\delta)^{t}}}{T}
$$

where the strict equality derives from the above expression for standard deviation of net lifetime transfers, and denotes as $\sigma$ the elasticity of $U^{\prime}$. Marginal utility is more equal when marginal utility is less elastic (i.e., smaller $\sigma$ ), relevant lifetimes are longer (i.e., higher $T$ ), or a person's work status is less correlated over time on account of tastes (i.e., larger $\delta$ ).

To numerically compare the distributions of reservation wages with and without tastes insurance, we need only to choose numerical values for $\sigma, \delta, T$, and $\operatorname{sd}(\ln \gamma)$ to use in the formulas (A-4) and (A-5). Take, for example, $T=40$ years and logarithmic utility $(\sigma=1)$. With these parameters, the cross-sectional standard deviation of log marginal utility is about 0.3 , and fairly insensitive to $\delta$ except near the extremes $\delta=0$ and $\delta=1$, so I set $\delta=0.4$.

$\operatorname{sd}(\ln \gamma)=0.8$ implies that the Frisch wage elasticity of labor supply is one in the neighborhood of $w=1 / T$ and less than one elsewhere. Using these numerical parameters and the formula (A-4), we have that the standard deviation of reservation wages without taste insurance is, as a fraction of the standard deviation with taste insurance, in the interval [0.63,1.07]. A 0.3 correlation between marginal utility of wealth and one period's disutility of work implies that $\operatorname{sd}\left(\ln \hat{w}_{t}^{i}\right)$ is 0.77 , or $96 \%$ percent of $\operatorname{sd}(\ln \gamma)$.

${ }^{22}$ Leisure is a normal good, which implies that tastes insurance enhances (lowers) the lifetime consumption of high $\gamma$ (low $\gamma$ ) persons by no more than the amount of the transfer $P(\Gamma)$. 


\section{References}

Ashenfelter, Orley. "Unemployment as Disequilibrium in a Model of Aggregate Labor Supply." Econometrica. 48(3), April 1980: 547-64.

Barro, Robert J. and Chaipat Sahasakul. "Measuring the Average Marginal Tax Rate from the Individual Income Tax." Journal of Business. 56 (October 1983): 419-52.

Ben-Porath, Yoram. "Labor-Force Participation Rates and the Supply of Labor." Journal of Political Economy. 81(3), May-June 1973: 697-704.

Bowen, William G. and T. Aldrich Finegan. The Economics of Labor Force Participation. Princeton, N.J., Princeton University Press, 1969.

Chapman, Sir Sydney John. "Hours of Labor." Economic Journal. 19, September 1909: 354-79.

Cho, Jang-Ok. "Ex post Heterogeneity and the Business Cycle." Journal of Economic Dynamics and Control. 19(3), April 1995: 533-51.

Cho, Jang-Ok and Thomas F. Cooley. "Employment and Hours over the Business Cycle.” Journal of Economic Dynamics and Control. 18(2), March 1994: 411-32.

Christiano, Lawrence and Martin Eichenbaum. "Current Real-Business-Cycle Theories and Aggregate Labor-Market Fluctuations.” American Economic Review. 82(3), June 1992: 430-50.

Cole, Harold L. and Edward C. Prescott. "Valuation Equilibrium with Clubs." Journal of Economic Theory. 74(1), May 1997: 19-39.

Coleman, Thomas Sedgwick. "Essays on Aggregate Labor Market Business Cycle Fluctuations." $\mathrm{PhD}$ dissertation, University of Chicago, December 1984.

Cooley, Thomas F. and Gary D. Hansen. "The Inflation Tax in a Real Business Cycle Model." American Economic Review. 79(4), September 1989: 733-48.

Crucini, Mario J. and James Kahn. "Tariffs and Aggregate Economic Activity: Lessons from the Great Depression.” Journal of Monetary Economics. 38(3), December 1996: 427-67.

Diamond, Peter A. and James A. Mirrlees. "A Model of Social Insurance with Variable Retirement." Journal of Public Economics. 10(3), December 1978: 295-336.

Diamond, Peter A. and James A. Mirrlees. "Payroll-Tax Financed Social Insurance with Variable Retirement." Scandinavian Journal of Economics. 88(1), 1986: 25-50. 
Eissa, Nada and Jeffrey B. Liebman. "Labor Supply Response to the Earned Income Tax Credit." Quarterly Journal of Economics. 111(2), May 1996: 605-37.

Ghez, Gilbert R. and Gary S. Becker. The Allocation of Time and Goods over the Life Cycle. New York: Columbia University Press (for the NBER), 1975.

Greenwood, Jeremy and Zvi Hercowitz. "The Allocation of Capital and Time over the Business Cycle." Journal of Political Economy. 99(6), December 1991: 1188-1214.

Grunfeld, Yehuda and Zvi Griliches. "Is Aggregation Necessarily Bad?" Review of Economics and Statistics. 42(1), February 1960: 1-13.

Hall, Robert E. and Alvin Rabushka. The Flat Tax. 2nd edition. Stanford, CA: Hoover Institution Press, 1995.

Hamermesh, Daniel S. “Aggregate Employment Dynamics and Lumpy Adjustment Costs." Carnegie-Rochester Conference Series on Public Policy. 33(0), Autumn 1990: 93-130.

Hamilton, James D. "A Neoclassical Model of Unemployment and the Real Business Cycle." Journal of Political Economy. 96(3), June 1988: 593-617.

Hanoch, Giora. "Weeks and Hours in the Theory of Labor Supply." in James P. Smith, ed. Female Labor Supply. Princeton, NJ: Princeton University Press, 1980: 119-65.

Hansen, Gary D. "Indivisible Labor and the Business Cycle." Journal of Monetary Economics. 16(3), November 1985: 309-27.

Hansen, Gary D. and Thomas J. Sargent. "Straight Time and Overtime in Equilibrium." Journal of Monetary Economics. 21(2,3), Mar/May 1988: 281-308.

Hansen, Lars Peter and James J. Heckman. “The Empirical Foundations of Calibration.” Journal of Economic Perspectives. 10(1), Winter 1996: 87-104.

Hausman, Jerry A. "Taxes and Labor Supply." in Alan J. Auerbach and Martin Feldstein, eds. Handbook of Public Economics. Amsterdam: North-Holland, 1985.

Heckman, James J. "A Partial Survey of Recent Research on the Labor Supply of Women." American Economic Review. 68(2), May 1978: 200-7.

Heckman, James J. "What has been Learned about Labor Supply in the Past Twenty Years?" American Economic Review. 83(2), May 1993: 116-21.

Heckman, James J. and Guilherme Sedlacek. "Heterogeneity, Aggregation, and Market Wage Functions: An Empirical Model of Self-Selection in the Labor Market." Journal of Political 
Economy. 93(6), December 1985: 1077-1125.

Hildenbrand, Werner. Core and Equilibria of a Large Economy. Princeton, NJ: Princeton University Press, 1974.

Hoynes, Hilary Williamson. "Welfare Transfers in Two-Parent Families: Labor Supply and Welfare Participation under AFDC-UP.” Econometrica. 64(2), March 1996: 295-332.

Houthakker, Hendrik S. "The Pareto Distribution and the Cobb-Douglas Production Function in Activity Analysis." Review of Economic Studies. 23, 1955: 27-31.

Lucas, Robert E., Jr. “Capacity, Overtime, and Empirical Production Functions.” American Economic Review. 60(2), May 1970: 23-27.

Lucas, Robert E., Jr. and Leonard A. Rapping. "Real Wages, Employment, and Inflation." Journal of Political Economy. 77(5), September 1969.

Kydland, Finn and Edward C. Prescott. "Hours and Employment Variation in Business Cycle Theory." Economic Theory. 1(1), January 1991: 63-81.

MaCurdy, Thomas E. "An Empirical Model of Labor Supply in a Life Cycle Setting." Journal of Political Economy. 88 (December 1981): 1059-85.

MaCurdy, Thomas E. "Work Disincentive Effects of Taxes: A Reexamination of Some Evidence." American Economic Review. 82 (May 1992): 243-49.

Marshall, Alfred. Principles of Economics. 8th edition. Philadelphia: Porcupine Press, 1920/1990.

Mincer, Jacob. "Labor Force Participation of Married Women: A Study of Labor Supply.” in H.G. Lewis, ed. Aspects of Labor Economics. Princeton: Princeton University Press, 1962.

Mincer, Jacob and Haim Ofek. "The Distribution of Lifetime Labor Force Participation of Married Women: Comment.” Journal of Political Economy. 87(1), February 1979: 197-201.

Mulligan, Casey B. "Substitution over Time: Another Look at Labor Supply over the Life Cycle." Macroeconomics Annual 1998, 1998a.

Mulligan, Casey B. "Pecuniary Incentives to Work in the U.S. during World War II." Journal of Political Economy. 106(5), October 1998b: 1033-77.

Mulligan, Casey B. "Microfoundations and Macro Implications of Indivisible Labor." NBER Working paper \#7116, May 1999.

Mulligan, Casey B. “Aggregate Implications of Composition Bias." Working paper, University of Chicago, October 2000. 
Mulligan, Casey B. and Xavier X. Sala-i-Martin. "Social Security in Theory and Practice I." NBER working paper no. 7118, May 1999.

Ohanian, Lee E. "The Macroeconomic Effects of War Finance in the United States: World War II and the Korean War.” American Economic Review. 87 (March 1997): 23-40.

Pencavel, John. "Labor Supply of Men: A Survey." in Orley Ashenfelter and Richard Layard, eds. Handbook of Labor Economics. Amsterdam: North Holland, 1986.

Plosser, Charles I. "Understanding Real Business Cycles." Journal of Economic Literature. 3(3), Summer 1989: 51-77.

Rogerson, Richard. "Indivisible Labor, Lotteries and Equilibrium." Journal of Monetary Economics. 21(1), January 1988: 3-16.

Roy, Andrew D. "Some Thoughts on the Distribution of Earnings." Oxford Economic Papers. 3, 1951: $135-46$.

Smith, James. "Family Labor Supply over the Life Cycle." Explorations in Economic Research. 4(2), Spring 1977: 205-76.

Wu, Yangru and Junxi Zhang. "Endogenous Markups and the Effects of Income Taxation: Theory and Evidence from OECD Countries." Journal of Public Economics. 77(3), September 2000: 383-406. 